\title{
A Study on the Mechanisms of Interaction between Deep Foundation Pits and the Pile Foundations of Adjacent Skewed Arches as well as Methods for Deformation Control
}

\author{
Kai Cui ${ }^{1 D},{ }^{1}$ Jun Feng $\left(\mathbb{D},{ }^{2}\right.$ and Chengyong $\mathrm{Zhu}^{2}$ \\ ${ }^{1}$ Key Laboratory of High-Speed Railway Engineering of the Ministry of Education, Southwest Jiaotong University, \\ Chengdu, Sichuan 610031, China \\ ${ }^{2}$ School of Civil Engineering, Southwest Jiaotong University, Chengdu 610031, China \\ Correspondence should be addressed to Jun Feng; fengjun4316@163.com
}

Received 21 January 2018; Revised 4 March 2018; Accepted 12 March 2018; Published 17 April 2018

Academic Editor: Changzhi Wu

Copyright (c) 2018 Kai Cui et al. This is an open access article distributed under the Creative Commons Attribution License, which permits unrestricted use, distribution, and reproduction in any medium, provided the original work is properly cited.

\begin{abstract}
The construction of deep foundation pits is characterized by heavy loads on pile foundations, complex interactions between the foundation pit and pile foundations, and stringent requirements for deformation control. In this work, FLAC3D was used to perform computational analyses on the displacement responses of pile caps and the retaining walls of foundation pits in a variety of cases and reinforcement schemes. The computational results indicate that the piles of skewed arches interact with the retaining walls of the foundation pits through soil masses. We also revealed the mechanism by which deep foundation pits interacted with the pile foundations of adjacent skewed arches. Based on the mechanisms of interaction between foundation pit excavations and the piles of skewed arches, we proposed three reinforcement schemes for controlling the deformations associated with these interactions. The arched wall reinforcement scheme could provide a satisfactory result in terms of the control of horizontal displacements in the pile foundations and project costs.
\end{abstract}

\section{Introduction}

As society continues to grow, municipal projects like subways are becoming increasingly integrated with large public buildings. The simultaneous appearance of foundation pits and pile foundations is thus becoming increasingly probable. However, the excavation of foundation pits will affect adjacent pile foundations via excavation-induced movements in soil mass outside the foundation pit; the sliding soil layers also generate additional displacements and bending moments in adjacent piles. Deep foundation pit projects are characterized by large pile loads, high design risks and difficulties, complex foundation pit-pile interactions, and stringent demands for deformation control [1-6]. Therefore, it is necessary to conduct studies on the interactions between foundation pits and their adjacent piles, as well as techniques for deformation control.

At present, a number of researchers have studied the interactions of foundation pits with adjacent piles and obtained several notable results. Du and Yang [7] set up interfacial sliding blocks between piles and soils and defined a unified ultimate soil resistance for soil masses based on elasticity theory and $p-y$ curves; on this basis, Du and Yang scrutinized the plastic yield of soil masses and proposed an elastoplastic solution for the effects of foundation pit excavations on their adjacent pile foundations. Chen et al. [8] used the Plaxis program to perform two-dimensional (2D) numerical analyses on the processes of foundation pit excavations with pile-row supports to simulate a number of factors by which foundation pit excavations affected their adjacent pile foundations. Du and Yang [9] reinforced the passive zone inside the foundation pits and soil masses outside of the pit to increase the strength and deformation resistance of soil masses and performed analyses on the reinforcement measures that were taken when excavations induced excessively large deformations in adjacent pile foundations. Zheng et al. [10] performed measurements during the excavation of foundation pits and found that these 
excavations significantly affected nearby pile foundations. Furthermore, when large gaps were used in the pile-rows, it was found that the horizontal displacement in the waterstopping curtain could exceed that of the pile-rows. Based on the ABAQUS finite element analysis program, Zheng et al. [11] performed Mohr-Coulomb constitutive model analyses on the excavation of foundation pits, thus obtaining the subsidences and deformation patterns of pier piles close to the foundation pit during these excavations. Gong et al. [12] compared theoretical results with experimental results and analyzed how the reduction factor for lateral pile resistance is related to factors such as the excavation depth of the foundation pit, side length, length-to-width ratio, and pile length. Ong et al. [13] conducted a series of centrifuge model tests to investigate the behavior of a single pile subjected to excavation-induced soil movements behind a stable retaining wall in clay. The results reveal that, after the completion of soil excavation, the wall and the soil continue to move and such movement induces further bending moment and deflection on an adjacent pile. Zhang et al. [14] proposed a two-stage analysis method to study the behavior of pile foundations subjected to excavation-induced ground movements. This method can take the influence of working loads acting on pile heads into account and overcome some deficiencies of existing methods. Then, the proposed method is verified by comparing the calculated results with boundary element solutions and centrifuge test data. Lee [15] built a three-dimensional numerical model to study the behavior of a single pile and adjacent tunneling excavation in the lateral direction. The numerical analyses included comparisons between the current study, previous elastic solutions, and advanced 3D elastoplastic analyses. Bilotta and Russo [16] computed the effectiveness of a simple row of piles induced by the tunneling excavation by means of three-dimensional finite element analyses, thus allowing for an investigation of the relationship between performance and simple geometrical parameters. The results of centrifuge testing were reported and used as a benchmark. The potential damage has been quantified in this work, taking into account both the settlement profile and the horizontal strain induced at the ground surface by the tunneling excavation.

As shown in Figure 1(a), this study targeted the foundation pit of the Shuangliu airport (T2 Terminal) station (a railway station in Chengdu, China) with a length of about $980 \mathrm{~m}$, and its maximum excavation depth and width are $22 \mathrm{~m}$ and $57 \mathrm{~m}$, respectively. The length of the subway foundation pit within the area of the skewed arch pile caps of the airport terminal is almost $600 \mathrm{~m}$ long, and the clearance between the foundation pit and the pile foundations is only $12 \mathrm{~m}$. There are 16 skewed arch piles on the side of the terminal facing the subway station, and the dimensions of each pile cap are $20 \mathrm{~m} \times 20 \mathrm{~m} \times 3.5 \mathrm{~m}$. There are 15 manually drilled piles under the pile caps, and these bear the loads of the skewed arch structure of the terminal. The standard load values of the skewed arch are as follows: a horizontal reaction of $12,160 \mathrm{kN}$, a vertical force of $11,200 \mathrm{kN}$, and a bending moment of $23,980 \mathrm{kN} \cdot \mathrm{m}$. The permissible horizontal deformation in each pile cap is $\leq 8 \mathrm{~mm}$. This project is characterized by large loads on the piles of the skewed arches, complex interactions between the subway foundation pit and the terminal pile foundations, stringent deformation control requirements, and high levels of difficulty in the design and construction of the pit foundation itself.

Though the above previous researches fully studied the influence of foundation pit excavation on the deformation of pile foundation, a lot of experience has been gained in design and construction of foundation pit. However, deep foundation pit does not appear often at the same time with inclined arch group pile foundation, which is the case of Shuangliu airport station. As the clearance between the foundation pit and the skewed arch terminal piles is small and the horizontal reaction transferred by the skewed arch structure onto its pile foundations is large, the excavation of the deep foundation pit and the loading of the skewed arch piles will inevitably interact with each other. Hence, an understanding of the mechanisms of interaction between these structures is a necessary basis for the design of deformation control measures. In the present literature, analyses on the mechanisms of interaction of these structures and studies on the control of their deformations are rather scarce.

In summary, numerical analysis was used in this work to study the mechanisms of interaction between the piles of skewed arches and deep foundation piles and techniques for the control of deformations associated with these interactions. The findings of this study can be directly applied to the construction design of subway foundation pits.

\section{Numerical Analysis on the Impacts of Deep Foundation Pit Excavations on the Deformations of Skewed Arch Pile Foundations}

2.1. Computational Domain and Loads. FLAC3D was used to compute the effects of the excavation and reinforcement processes of the deep foundation pit on the pile foundations of the skewed arches. A strip of soil between two skewed arch pile caps in a central area of the airport was selected as the focus for this study, as shown in Figure 1(a). One of these skewed arch pile caps was selected as the subject of our simulations. The excitation loads are shown in Figure 1(b); the horizontal reaction was $12,160 \mathrm{kN}$, the vertical force was $11,200 \mathrm{kN}$, and the bending moment was $23,980 \mathrm{kN} \cdot \mathrm{m}$.

2.2. Computational Model. Because FLAC3D directly constructs finite differences in its computations (unlike the CAE program), its three-dimensional (3D) mesh is constructed around the geometry of the actual physical object [17-21]. However, the preprocessing of complex grids in FLAC3D is somewhat inadequate, as a result. Therefore, the physical model in the computational domain was modeled using hexahedral meshing in ANSYS. Data interface programs were then used to import the ANSYS element and node data into FLAC3D. As shown in Figure 2(a), beam elements (BEAM structural unit) were used to simulate the 1st- and 2nd-row concrete cross supports, 3rd- and 4th-row steel supports, the support column bearing the four rows of cross 


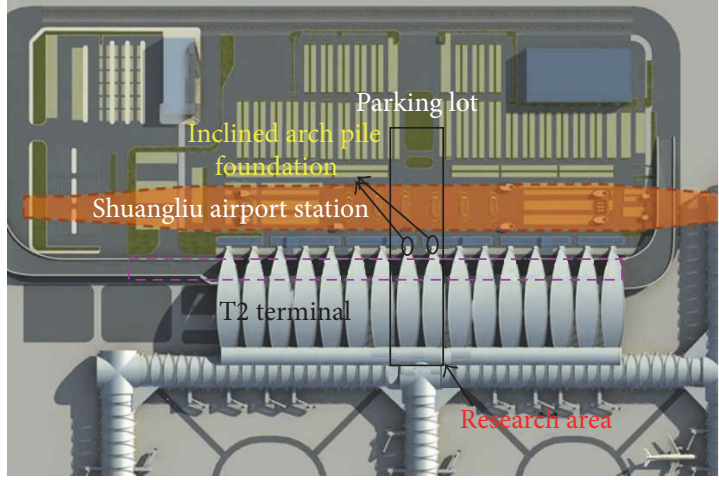

(a) Schematic diagram of the computational domain

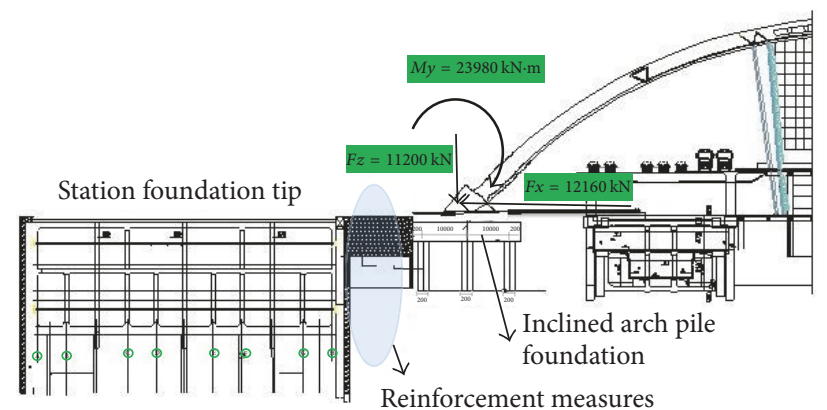

(b) Force diagram of the computational domain

FIGURE 1: Schematic diagram and force diagram of the computational domain.

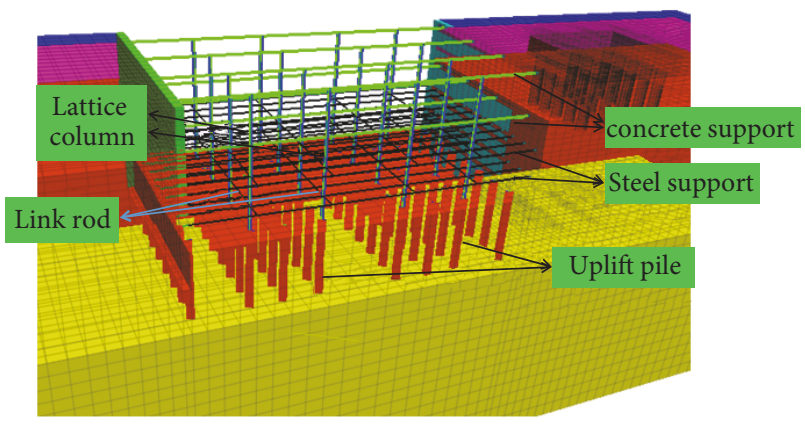

(a) Local structural element

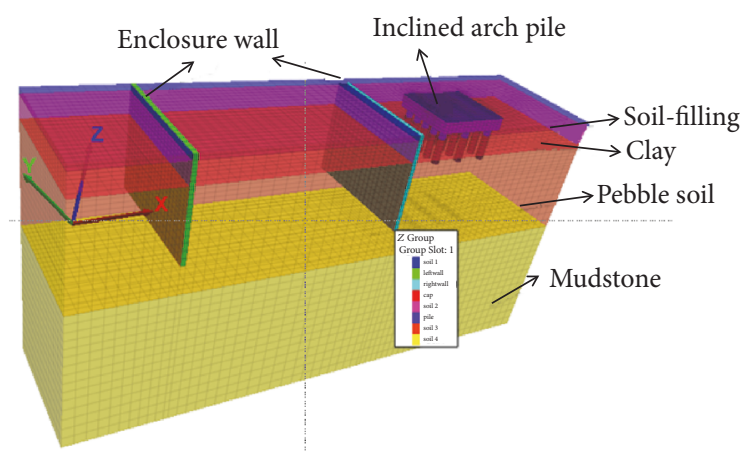

(b) Finite element model

FIGURE 2: Finite element model of the station foundation pit.

supports, and the tie-rods connecting the 3rd- and 4th-row steel supports. Because an appropriate stiffness parameter could not be determined for the pile elements in FLAC3D (PILE structural unit) and because the tension piles at the bottom of the pit are not the main focus of this study, the tension piles at the bottom of the pit were simulated using beam elements to simplify the computational model. Based on the principles of bending stiffness equivalence, the retaining piles on either side of the foundation pit were reduced to a solid continuous underground concrete wall. The skewed arch pile foundations were simulated using solid mesh elements. In FLAC3D, bending moments cannot be directly applied onto mesh nodes, which is necessary for simulating the loads borne by the pile cap of the skewed arch piles. Therefore, a short vertical beam with sufficient stiffness was set in the pile cap during the modeling, which is rigidly connected to the solid elements of the pile cap. This is similar to welding the short beam to the pile cap, which is largely consistent with actual scenarios. In this way, forces and bending moments can be applied onto the top node of the short beam, thus circumventing the need to equate forces to bending moments via the equivalence of forces. Constraints were applied in directions corresponding to the four lateral sides and bottom of the model; since FLAC3D uses Newton's Laws, we effectively constrained the node velocities on each of these surfaces. During the modeling of structural elements, the connections between different structural elements were handled using shared nodes. However, there are slight discrepancies between this method and actual scenarios; for example, lattice columns should be connected to steel supports through hinged joints, and the connection of tie-rods to steel supports should be similarly mediated by hinged joints, whereas the tension piles and support pillars should be connected via rigid connections. Nonetheless, the simplification of these connections will not significantly affect the overall computational results of extremely large models.

In order to reduce the influence of boundary constraints on the calculated stress field, the influence area of deep foundation pit is controlled by the depth of the hard soil behind the wall. The model range is $140 \mathrm{~m}$ (length $-x$ direction $) \times 34.6 \mathrm{~m}($ width $-y$ direction $) \times 70 \mathrm{~m}$ (height $-z$ direction). The number of units (element) is 77056 , and the number of nodes is 82940 . The retaining wall and soil are connected using the common node connection, inclined arch pile and soil node connection, steel support, reinforced concrete support, and pile and implantable structural unit simulation (embedded). In FLAC3D, the degree of freedom of the unit and the soil automatically couple.

Based on the methods described above, we obtained a finite element model for the subway foundation pit, as shown in Figure 2(b). We then assigned attributes and sectional 
TABLE 1: Material attributes and sectional characteristics of the structural elements.

\begin{tabular}{lccccc}
\hline Parameter & $\begin{array}{c}\text { 1st- and 2nd-row } \\
\text { concrete supports }\end{array}$ & $\begin{array}{c}\text { 3rd- and 4th-row steel } \\
\text { supports }\end{array}$ & $\begin{array}{c}\text { Tension piles at the } \\
\text { bottom of the pit }\end{array}$ & Lattice columns & Tie-rods \\
\hline $\begin{array}{l}\text { Elastic modulus } \\
\text { Poisson's ratio }\end{array}$ & 32500 & 206,000 & 30000 & 206000 & 206000 \\
$\begin{array}{l}\text { Moment of inertia in } \\
\text { the } y \text {-axis, } I_{y}\end{array}$ & 0.20 & 0.26 & 0.20 & 0.26 & 0.26 \\
$\begin{array}{l}\text { Moment of inertia in } \\
\text { the } z \text {-axis, } I_{z}\end{array}$ & 0.0427 & 0.00131 & 0.102 & 0.00299 & 0.00035 \\
$\begin{array}{l}\text { Polar moment of } \\
\text { inertia, } J\end{array}$ & 0.0667 & 0.00131 & 0.102 & 0.00089 & 0.0017 \\
$\begin{array}{l}\text { Cross-sectional area, } \\
\text { A }\end{array}$ & 0.80 & 0.00262 & 0.204 & 0.00388 & 0.00205 \\
\hline
\end{tabular}

characteristics to the structural elements of the finite element model, as shown in Table 1. FLAC3D is a 3D finite difference program that was specifically developed for rocks and soil masses and therefore has extremely detailed settings in its constitutive soil models. The Mohr-Coulomb elastoplastic model can be used for most rock and soil engineering studies, and the parameters of these models are usually relatively easy to obtain. Therefore, soils with weaker levels of strength in the finite element model were modeled using the MohrCoulomb elastoplastic constitutive model. Chengdu clays were defined with a density of $1.98 \mathrm{~g} / \mathrm{cm}^{3}$, cohesion of $35 \mathrm{kPa}$, internal friction angle of $12^{\circ}$, elastic modulus of 7.2 MPa, and Poisson's ratio of 0.35 . Gravelly soils were assigned a density of $2.20 \mathrm{~g} / \mathrm{cm}^{3}$, internal friction angle of $40^{\circ}$, elastic modulus of $35 \mathrm{MPa}$, and Poisson's ratio of 0.29 . The mudstones in the model have a density of $2.20 \mathrm{~g} / \mathrm{cm}^{3}$, internal friction angle of $55^{\circ}$, elastic modulus of $400 \mathrm{MPa}$, and Poisson's ratio of 0.30 .

\subsection{Computational Procedure}

Step 1. The tension piles on the bottom of the pit, lattice columns, retaining walls, and skewed arch piles were assembled first. In terms of FLAC3D procedures, this corresponds to the setting of material attributes and the assembly of structural elements in the soil mass model, followed by a round of equilibration. The initial in situ stresses of the soils were then calculated.

Step 2. The initial displacements produced by the initial stresses of the soil masses were reset, and excavation was performed up to $0.8 \mathrm{~m}$ below the surface, followed by equilibration.

Step 3. The 1st-row horizontal supports were mounted $0.5 \mathrm{~m}$ below the surface, followed by equilibration.

Step 4. The excavation was extended to $7.8 \mathrm{~m}$ below the surface, and partial stress release was performed over 1,000 iterations. The 2nd-row horizontal supports were then mounted, followed by equilibration.

Step 5. The excavation was extended to $12.3 \mathrm{~m}$ below the surface, followed by partial stress release over 1,000 iterations.

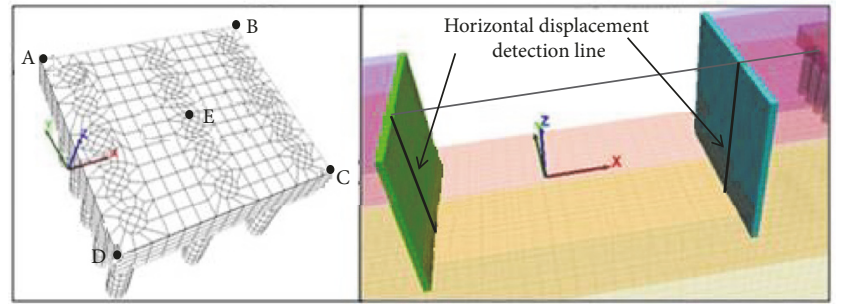

FIGURE 3: Displacement monitoring points on the skewed arch pile foundation and retaining walls.

The 3rd-row horizontal supports and tie-rods connected to these supports were then mounted, and the model was then equilibrated.

Step 6. The excavation was extended to $16.8 \mathrm{~m}$ below the surface, followed by partial stress release over 1,000 iterations. The 4th-row horizontal supports and their associated tie-rods were then mounted, and the model was equilibrated.

Step 7. The excavation was extended to $20.3 \mathrm{~m}$ below the surface, followed by equilibration. At this point, the excavation of soil masses for the foundation pit has been completed.

Step 8. The displacement data generated by the excavations were zeroed, and loads were applied onto the skewed arch pile foundations. A horizontal force of $F_{x}=12,160 \mathrm{kN}$, vertical force of $F_{z}=11,200 \mathrm{kN}$, and bending moment of $M_{y}=$ $23,980 \mathrm{kN} \cdot \mathrm{m}$ were applied on the central node of the upper surface of the pile cap. The model was then equilibrated.

2.4. The Layout of Monitoring Points. Prior to the numerical computations, the (four) corners and central point of the pile cap were set as monitoring points for displacement, as shown in Figure 3. The mesh nodes on two $y=20$ straight lines on the left and right retaining walls were selected as monitoring points for horizontal displacement. This setup allows for a detailed study on the displacement responses of the pile cap and retaining walls. The $\mathrm{A}$ and $\mathrm{D}$ monitoring points correspond to pile cap corners closer to the foundation pit, and the $\mathrm{AD}$ side is parallel to the $y$-axis of the model coordinate system. 


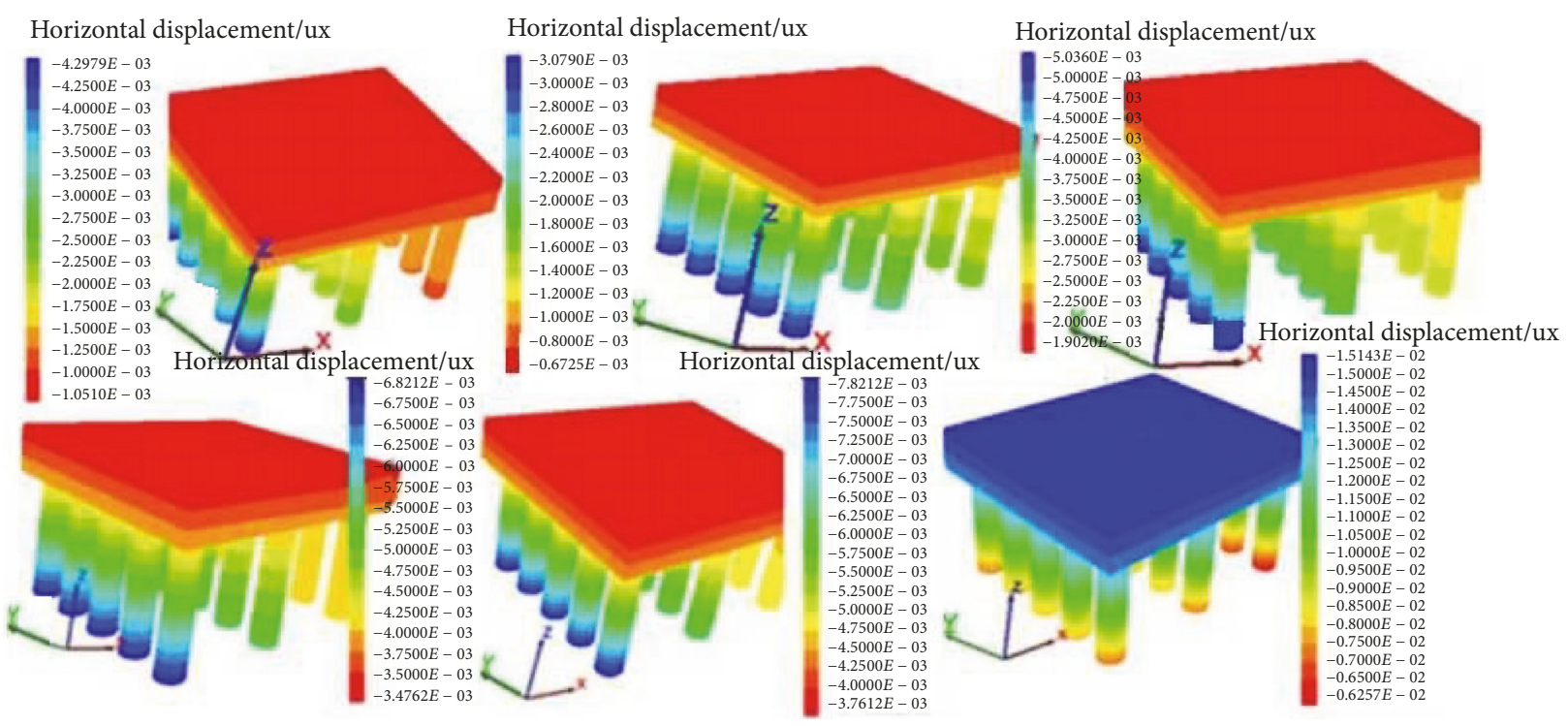

FIGURE 4: Contour maps of the pile cap horizontal displacement in each case.

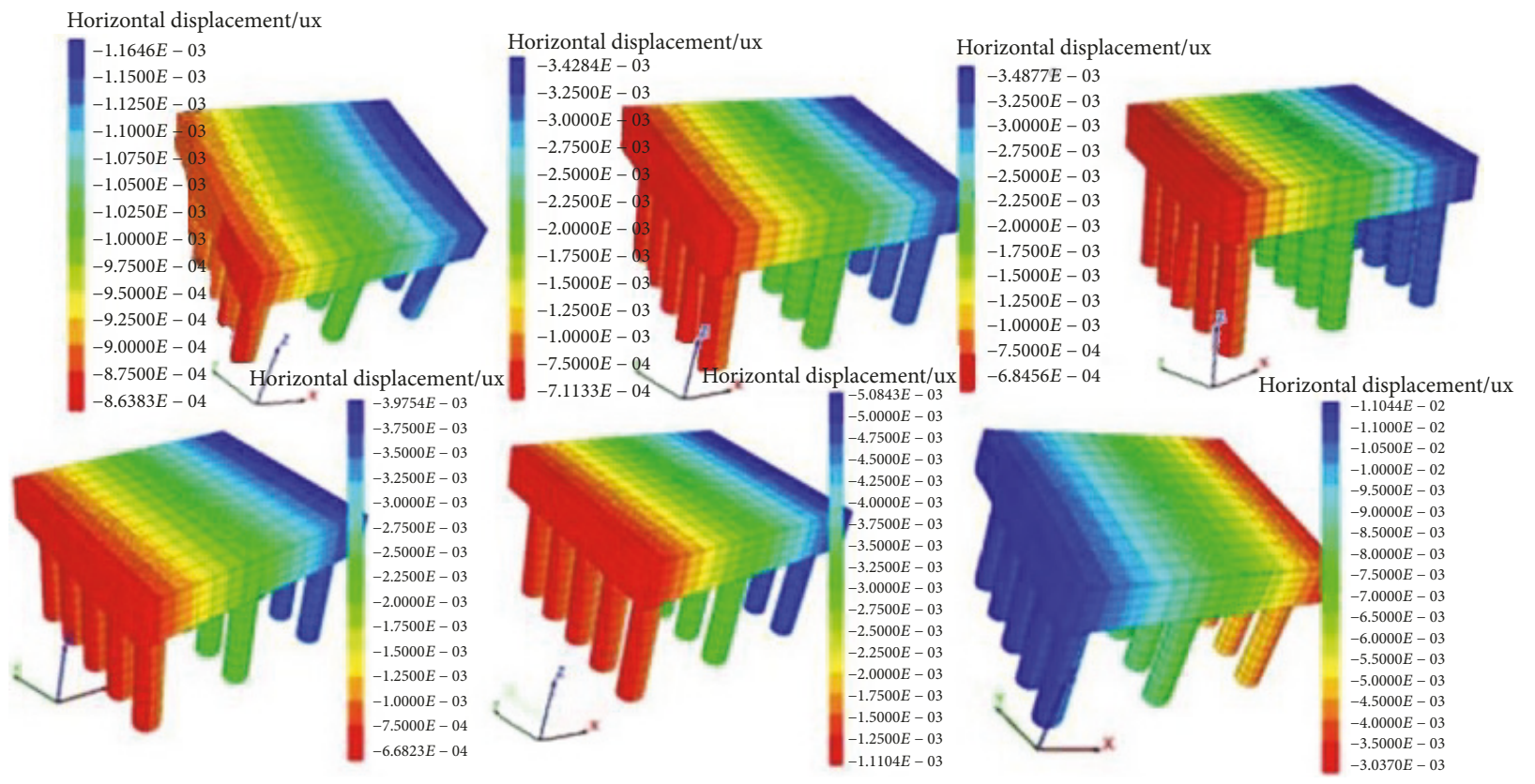

Figure 5: Contour maps of the pile cap vertical displacement in each case.

\section{Computational Analysis of the Skewed Arch Pile Foundations prior to Reinforcement}

3.1. The Displacement Responses of the Pile Cap. Based on the results of the numerical calculations, the horizontal and vertical displacements of the skewed arch piles were described using contour maps. To facilitate the discrimination of the contour maps, the mesh outlines are not shown when the horizontal displacement is shown, as is the case in Figures 4 and 5. In Figures 4 and 5, the images from left to right correspond to Cases 1-6. In Case 1, the excavation reached $0.8 \mathrm{~m}$ below the surface, and the 1st-row horizontal concrete supports have been mounted. In Case 2, the excavation has progressed to $7.8 \mathrm{~m}$ below the surface, and the 2 nd-row horizontal concrete supports have been mounted. In Case 3, the excavation has reached $12.3 \mathrm{~m}$, and the 3 rd-row horizontal steel supports and tie-rods have been mounted. In Case 4, the excavation is $16.8 \mathrm{~m}$ below the surface, and the 4 th-row horizontal steel supports and tie-rods have been mounted. In Case 5, the excavation has been completed (the excavation has reached $20.3 \mathrm{~m}$ below the surface, which is the bottom of the foundation pit). In Case 6, loads have been applied onto the skewed arch pile foundations (the displacements caused by the excavation have been zeroed). The horizontal and vertical 
TABLE 2: The horizontal and vertical displacements of the pile cap in each case.

\begin{tabular}{|c|c|c|c|c|c|c|c|}
\hline \multirow{2}{*}{ Monitoring points } & & \multicolumn{6}{|c|}{ Cases } \\
\hline & & Case 1 & Case 2 & Case 3 & Case 4 & Case 5 & Case 6 \\
\hline \multirow{5}{*}{ Horizontal displacement } & Corner A & 0.081 & 0.64 & 1.20 & 3.48 & 3.76 & 14.88 \\
\hline & Corner B & 0.093 & 0.7 & 2.07 & 3.56 & 3.86 & 15.06 \\
\hline & Corner C & 0.093 & 0.7 & 2.08 & 3.57 & 3.87 & 15.14 \\
\hline & Corner D & 0.081 & 0.64 & 1.20 & 3.48 & 3.77 & 14.95 \\
\hline & Corner E & 0.086 & 0.67 & 2.03 & 3.52 & 3.82 & 14.80 \\
\hline \multirow{5}{*}{ Vertical displacement } & Corner A & 0.89 & 0.75 & 0.59 & 0.70 & 1.15 & 10.83 \\
\hline & Corner B & 1.16 & 3.43 & 3.49 & 3.97 & 5.08 & 3.04 \\
\hline & Corner C & 1.15 & 3.39 & 3.45 & 3.94 & 5.05 & 3.21 \\
\hline & Corner D & 0.87 & 0.71 & 0.55 & 0.67 & 1.12 & 10.96 \\
\hline & Corner E & 1.04 & 2.13 & 2.11 & 2.42 & 3.20 & 7.83 \\
\hline
\end{tabular}

displacements in the skewed arch pile foundations at each monitoring point corresponding to each case are shown in Table 2.

In Table 2, it is shown that $\mathrm{A}$ and $\mathrm{D}$, which lie on the pile cap side closer to the foundation pit, have slightly smaller horizontal displacements compared to B and C, which are on the opposite side. This is because the displacements of the pile cap on the side closer to the foundation pit are restricted by retaining piles. Furthermore, the retaining piles have been reinforced in a timely manner in each excavation step, which subsequently restricts soil mass displacements between the pile cap and the retaining piles; however, the soil masses on the opposite side do not have any additional restraints. Therefore, the displacements of the pile cap corners on the side closer to the foundation pit are slightly lower than those on the opposite side, both during the excavation process and after the application of loads onto the pile cap. However, the data in Table 2 indicates that the differences between the horizontal displacements of the corners are very small. This is because the skewed arch pile foundations are substantially stiffer than the soil masses, and the former may be approximated as a rigid body. As a whole, the horizontal motions of the pile cap may be approximated as the movements of a rigid body. Furthermore, based on the changes in displacement in each excavation step, the horizontal displacements caused by the excavation of the foundation pit are quite small, even without any further reinforcement. By the end of the excavation, the cumulative horizontal displacement was only $3.8 \mathrm{~mm}$ or so (the central point of the pile cap, $\mathrm{E}$, is the reference in this case). Nonetheless, the application of loads onto the skewed arch's piles (including a horizontal force, vertical force, and bending moment) induces a horizontal displacement of $14.8 \mathrm{~mm}$. This displacement is enough to undermine the stability of the upper structures of the terminal. Therefore, it is necessary to reinforce the soil masses between the foundation pit and the skewed arch pile foundations.

Table 2 also indicates that the vertical displacements of $\mathrm{A}$ and $\mathrm{D}$ are slightly lower than those of $\mathrm{B}$ and $\mathrm{C}$. Significant differences in subsidence were generated between these corners with increasing excavation depth. The vertical displacement of the central point of the pile cap is essentially equivalent to the average vertical displacement of the four corners. The displacements of the pile cap side closer to the foundation pit are restricted by retaining piles, and the retaining piles are always reinforced in a timely manner in each excavation step, thus constraining the displacements of the strip of soil between the retaining piles and pile cap. However, the soil masses on the other side of the pile cap have no additional restraints. Therefore, the pile cap corners on the side adjacent to the foundation pit always have smaller vertical displacements than pile cap corners on the opposite side, both during the excavation process and after the application of loads onto the pile cap. However, upon the application of loads, the vertical displacement trends are completely reversed, as the pile cap corners on the side adjacent to the foundation pit have much greater subsidences than those of the opposite side. This is because the pile cap's displacements under the actions of the three aforementioned forces rotate in an anticlockwise direction around an axis parallel to the $y$-axis; consequently, there are highly significant differences in the subsidences of the pile cap's corners after loads have been applied. This is extremely likely to be detrimental for the stability of the upper structures of the terminal. Hence, it is necessary to reinforce the soil masses between the foundation pit and the pile foundations of the skewed arch.

3.2. The Displacements and Stress Responses of the Retaining Walls of the Foundation Pit. The horizontal displacements of the retaining wall monitoring points farther and closer to the pile foundations were extracted, as shown in Figure 6. In this figure, it is shown that the deformation state of the retaining walls of the foundation pit is generally consistent with Type 3 displacement state curves, prior to the application of loads onto the pile foundations of the skewed arch. After loads were applied onto the skewed arch piles, the horizontal displacements of the retaining wall closer to the piles exhibit a linear distribution along the wall, in the vertical direction, with the displacement being greatest at the top of the wall. This is because extremely large loads were applied at the central point of the upper surface of the pile cap. Upon the application of loads onto the skewed arch piles, the foundation pit retaining walls farther from the piles are 


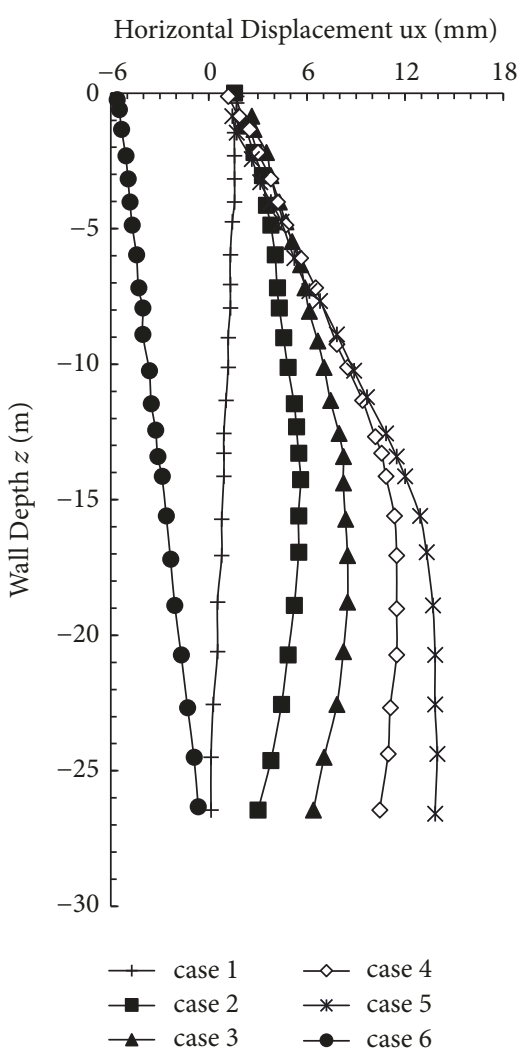

(a)

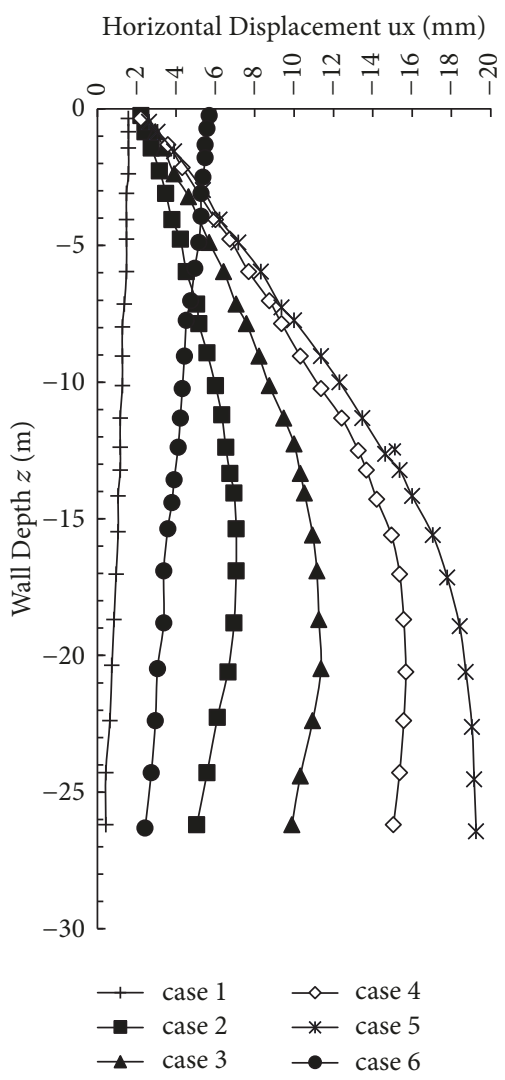

(b)

FIGURE 6: Horizontal displacements of the monitoring points on the retaining wall that are farther and closer to the pile foundations.

restrained by the retaining wall closer to the piles. Because axial forces and displacements are transferred to the farther retaining wall via horizontal supports, the distributions of its horizontal displacements are exactly opposite to that of the closer retaining wall: the displacements at the top of the wall are small, but large at the bottom.

\section{Computational Analysis on the Reinforced Skewed Arch Pile Foundations}

\subsection{Analyzing the Effects of Reinforcement via Isolation Piles and Jet-Grouted Piles (1st Reinforcement Scheme)}

4.1.1. Reinforcement Scheme. To ensure the safety of the terminal pile caps, soil reinforcement was performed on the retaining piles on the right side of the airport station and between the pile caps of the terminal; this reinforcement was performed via a combination of isolation piles and jetgrouted piles. Two rows of isolation piles were used, and the pile-rows were located $2.1 \mathrm{~m}$ from the edges of the pile cap; the diameter of the jet-grouted piles was $800 \mathrm{~mm}$. Zones A and $\mathrm{B}$ were defined according to the reinforcement requirements of the area. Zone A was reinforced with a pile overlap of $10 \mathrm{~cm}$, while Zone B was reinforced using a plum-shaped arrangement with a $1.4 \mathrm{~m}$ gap, as shown in Figure 7.

The parameters of the isolation piles were as follows: pile diameter $=1,500 \mathrm{~mm}$, interpile gap $=2.9 \mathrm{~m}$, pile length
$=20 \mathrm{~m}$, and absolute elevation of the top of the piles = $491.4 \mathrm{~m}$. The range of reinforcement and requirements of the jet-grouted piles were as follows: all of the upper soil masses needed to be reinforced; the slightly compacted gravel soils in which the piles were embedded are not smaller than $1 \mathrm{~m}$, and the length of the piles was approximately 7-9 m. During the construction, the pile lengths were determined according to the in situ geological conditions. Plate girders, whose sectional dimensions are $4.4 \mathrm{~m} * 0.6 \mathrm{~m}$, were set up on top of the piles. The absolute elevation of the plate girders was $491.9 \mathrm{~m}$, and they were set in a longitudinal layout. The reinforcement requirements of the soil masses are described as follows: after reinforcement, the deformation moduli of the soil masses in Zone A and Zone B must be not less than $80 \mathrm{MPa}$ and $20 \mathrm{MPa}$, respectively. During the numerical calculations, these deformation moduli were taken as the elastic moduli of the soil masses in Zones A and B, to ensure that the calculations lean towards conservative estimates. A finite element model of the reinforced subway foundation pit was constructed based on this reinforcement scheme, as shown in Figure 8.

4.1.2. The Displacement Responses of the Pile Caps. The horizontal and vertical displacements of the skewed arch pile foundations in each construction case are shown in Figures 9 and 10. After reinforcement, the horizontal and vertical displacements of the pile caps gradually increase 


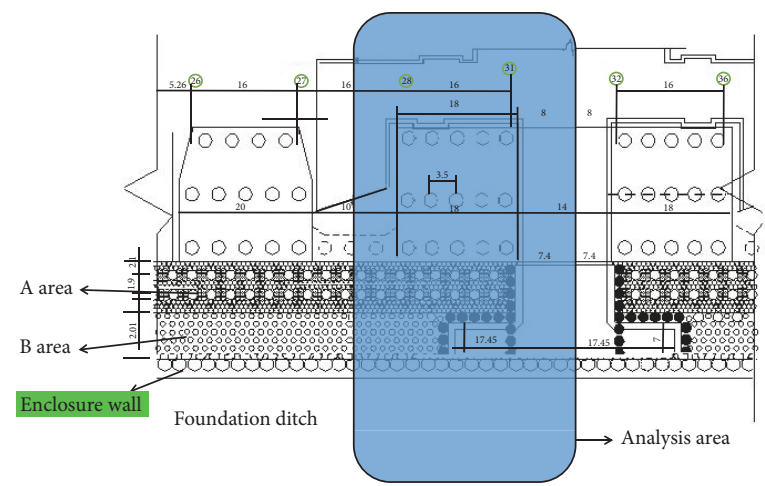

(a) Schematic diagram of the areas for soil mass reinforcement

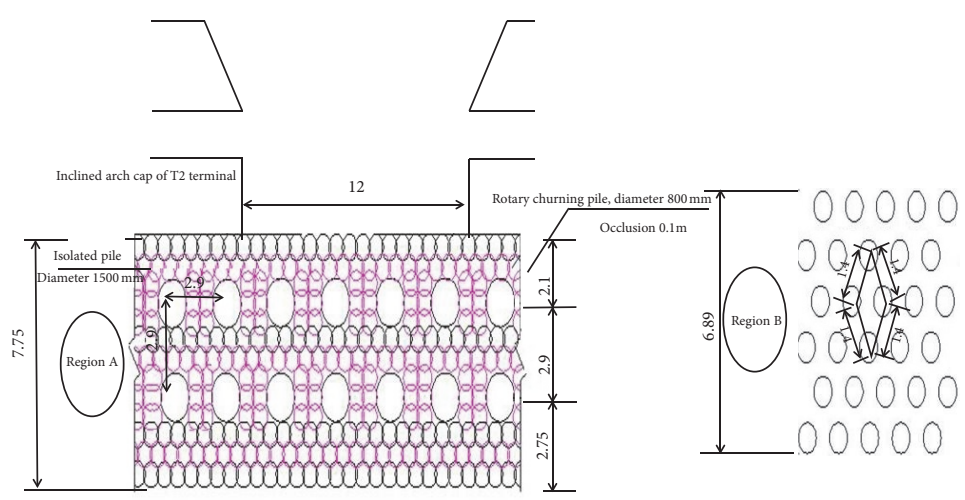

(b) Details of the reinforcement of Zones A and B

FIGURE 7: Schematic diagram of the isolation pile + jet-grouted pile reinforcement scheme.

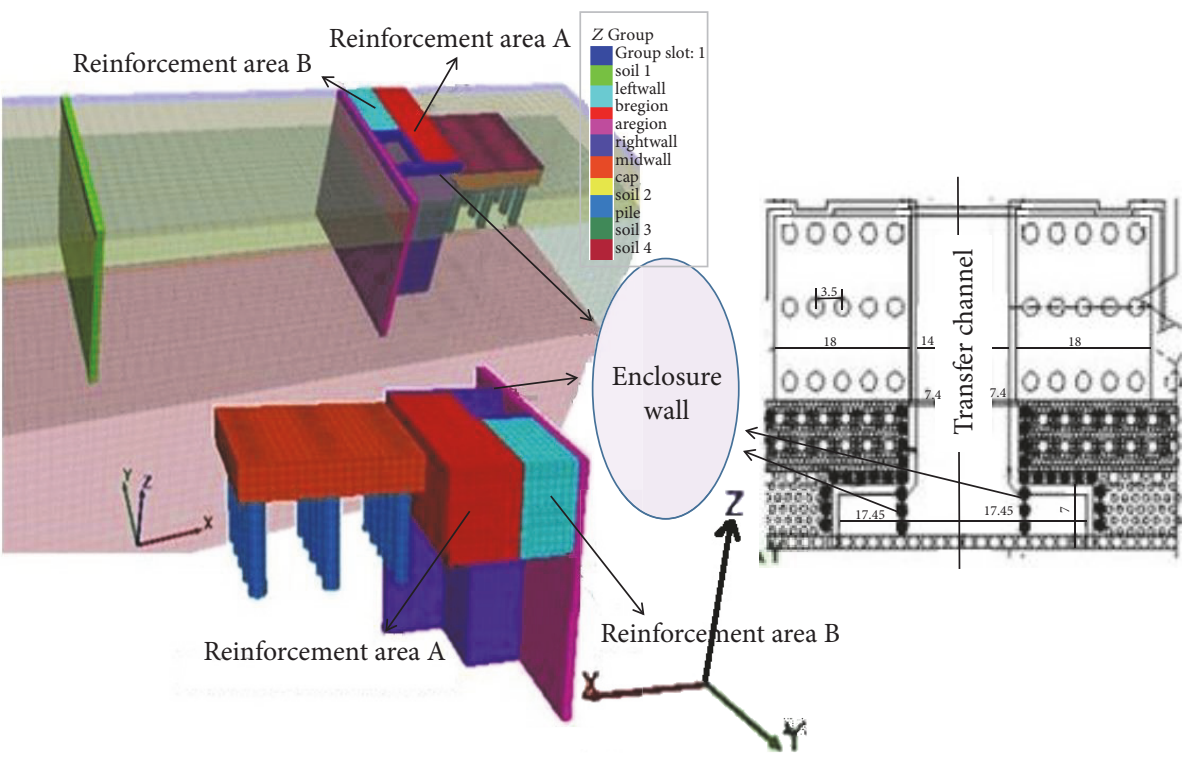

FIGURE 8: Finite element model of the reinforced subway foundation pit.

with each excavation step. At the end of the excavation, the horizontal and vertical displacements at the center of the pile cap were $2.92 \mathrm{~mm}$ and $1.04 \mathrm{~mm}$. This corresponds to $24 \%$ and $68 \%$ reductions in horizontal and vertical displacement, respectively, as compared to the unreinforced model. Based on the impacts of the foundation pit excavation on the horizontal displacement of the skewed arch pile foundations, the reinforcement effect is more obvious. Upon loading of these piles, the horizontal and vertical displacements at the center of the pile cap increased to $6.03 \mathrm{~mm}$ and $4.03 \mathrm{~mm}$, respectively. Compared to the unreinforced model, the horizontal displacement decreased by $59 \%$ while the 


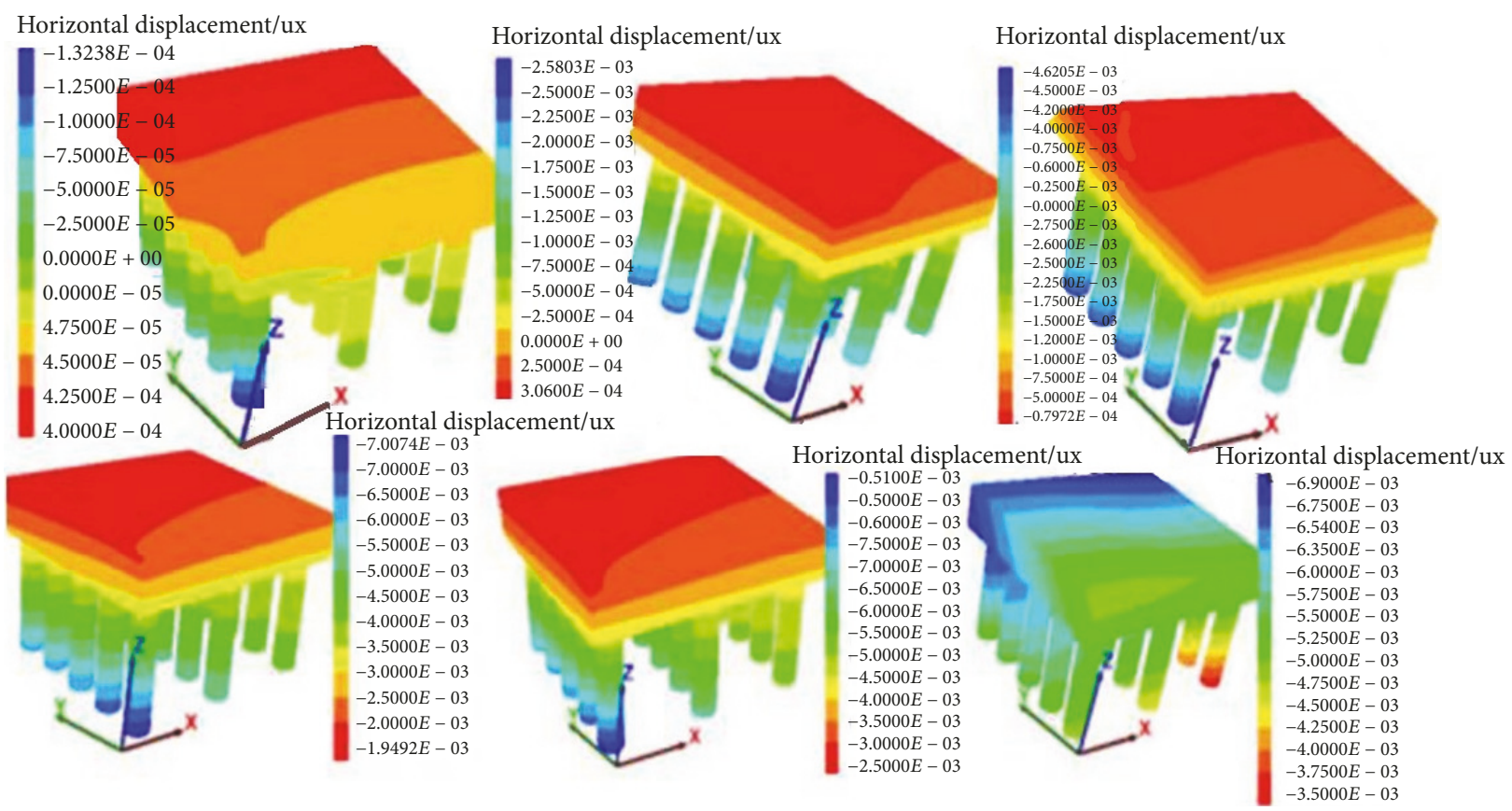

FIGURE 9: Contour maps of the horizontal displacements in each case.

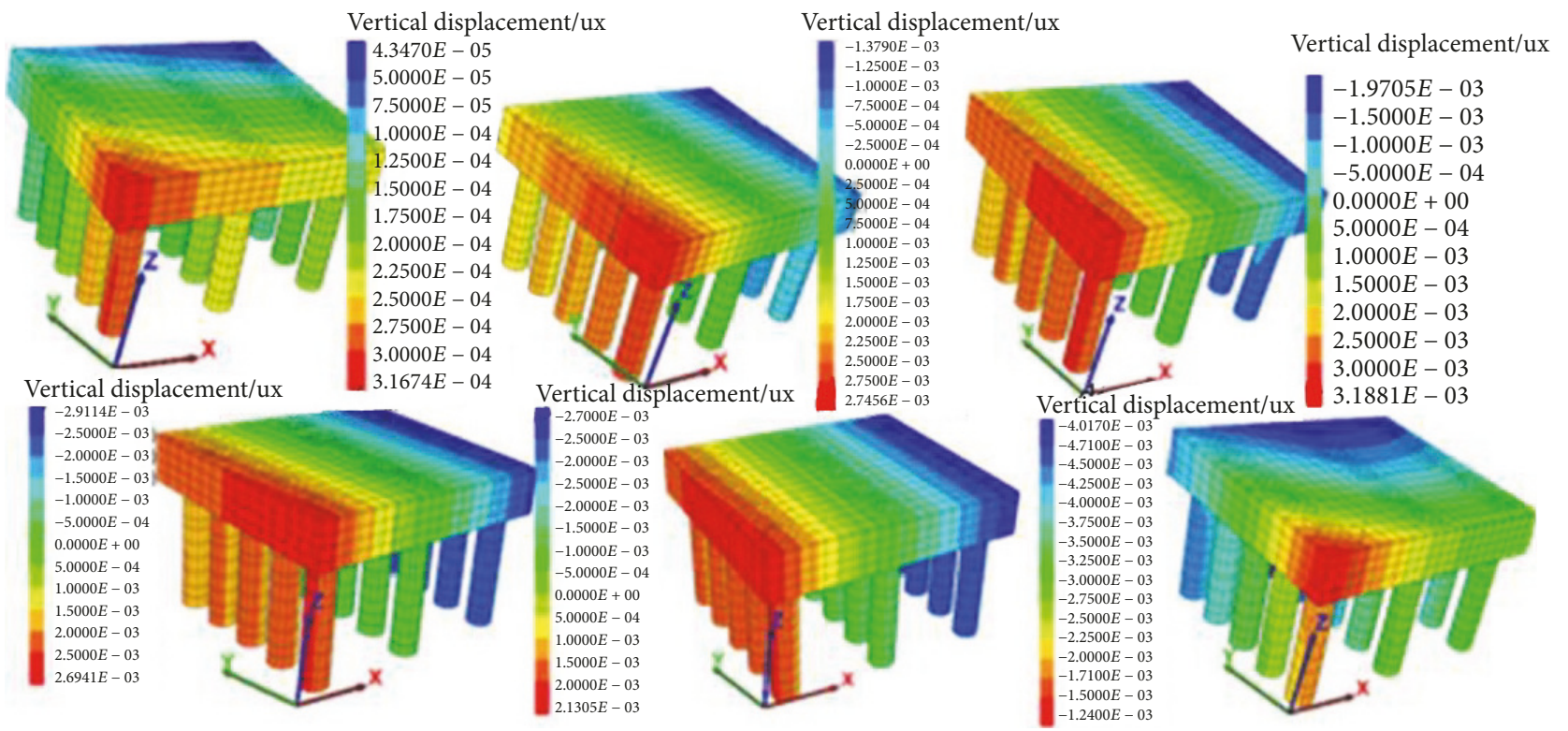

FIgURE 10: Contour maps of the vertical displacements in each case.

vertical displacement decreased by $49 \%$. It is shown that the reinforced zones have had a significant effect on restraining the horizontal displacements of the pile cap, especially after the loads were applied. Despite the conservative estimates of this computation, this reinforcement scheme has met the stability requirements of the upper structures of the terminal. Therefore, it is reasonable to postulate that this zonal reinforcement scheme will meet the safety requirements of the engineering applications.
4.1.3. The Displacement Responses of the Foundation Pit's Retaining Walls. The horizontal displacements extracted from the monitoring points on the retaining walls farther and closer to the pile foundations are shown in Figure 11. In this figure, it is shown that the maximum displacement in the retaining walls always occurs near the bottom of the excavated surface during the excavation process (in which internal reinforcement was added after each excavation step). Furthermore, these displacements generally increase 


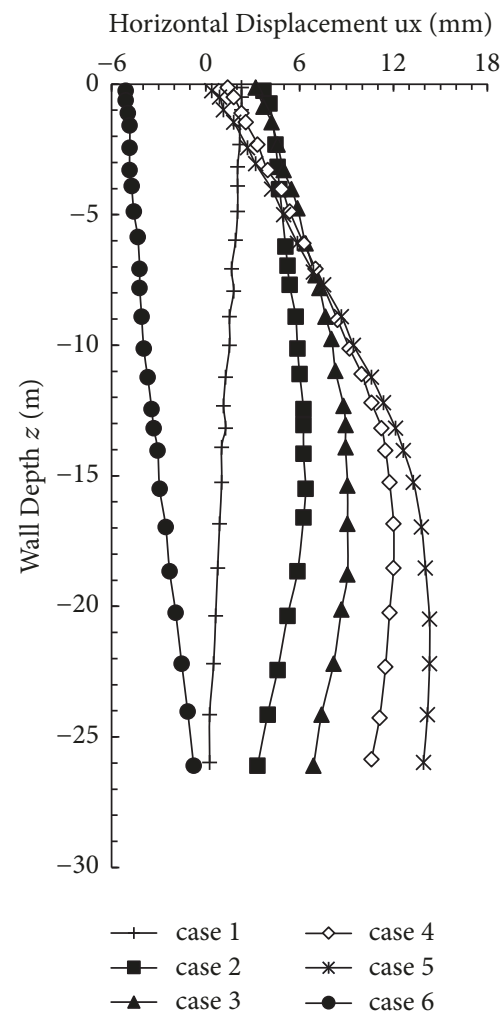

(a)

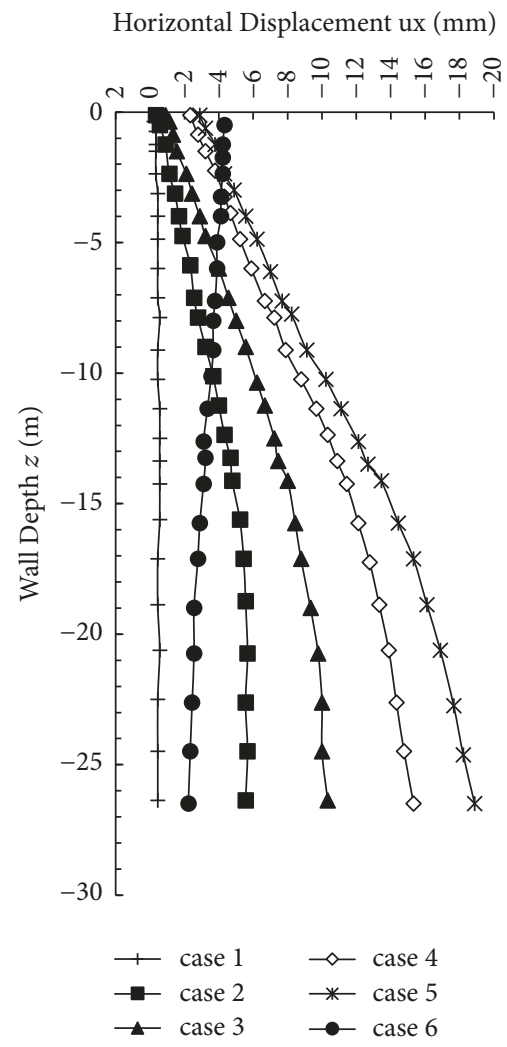

(b)

FIGURE 11: The horizontal displacements of the monitoring points on the retaining walls farther and closer to the pile foundations.

with increasing excavation depth. However, the displacements of the retaining wall farther from the skewed arch foundation piles exhibit a parabolic trend with respect to depth. The retaining wall closer to the foundation piles does not exhibit significant fluctuations in its horizontal displacements, because its displacements are restricted by the retaining walls of the transfer channel area. According to the deformation law of the whole wall, the numerical calculation is basically consistent with the displacement change law of the field monitoring.

4.2. Analyzing the Effects of Arched Wall Reinforcement (2nd Reinforcement Scheme). Here, we propose the installation of arched walls between the skewed arch pile foundations and the foundation pit retaining walls to reduce project costs and control the horizontal displacements of the skewed arch piles. The effects of this method are analyzed in this section. It is well understood that arched structures have excellent spanning capabilities and are mechanically sound. As the application of external loads on arched structures mainly results in compressive forces, the bending deformations of its members are generally quite small. The construction of arched structures using materials with high compressive strengths will contribute to the strengths of these materials. However, horizontal reactions will be generated around the abutments of an arched structure, and these reactions are very large when the span is large. These forces are both difficult and costly to deal with. Therefore, it is necessary to pay attention to the handling of the foot of the arch during the selection of arched structures.

4.2.1. Selection of an Arched Structure. To understand the mechanical characteristics of different arch structures from the perspective of structural stresses, we selected arched wall structures that are suitable for 3D numerical analysis. Using ANSYS, we analyzed the mechanical characteristics of a parabolic arch and an arc-shaped arch that have the same span and arc height, and a parabolic arch with the same arc height but different span. Concrete was used as the material of these structures, and the sections are arched wall sections of unit height. In the structural analysis, if we assume that the height of the arched wall is $5 \mathrm{~m}$ and the $12,160 \mathrm{kN}$ horizontal force acting on the skewed arch pile foundations is uniformly applied across the crown of the arched wall, the force shared by a unit height of the arched wall is then $20 \%$ of the total force $(2,432 \mathrm{kN})$. This was used to construct the finite element model of the arched walls' member systems. The contour maps of the bending moments, shear forces, and axial forces that were computed for the three aforementioned arched structures are shown in Figure 12. The bending moments, shear forces, and axial forces that were extracted from the key positions of each arched structure are shown in Table 3. In Table 3, it may be inferred that a parabolic arch performs better than an arc-shaped arch.

4.2.2. Displacement Response of the Pile Cap. A parabolic arched structure was used to reinforce the foundation pit of 

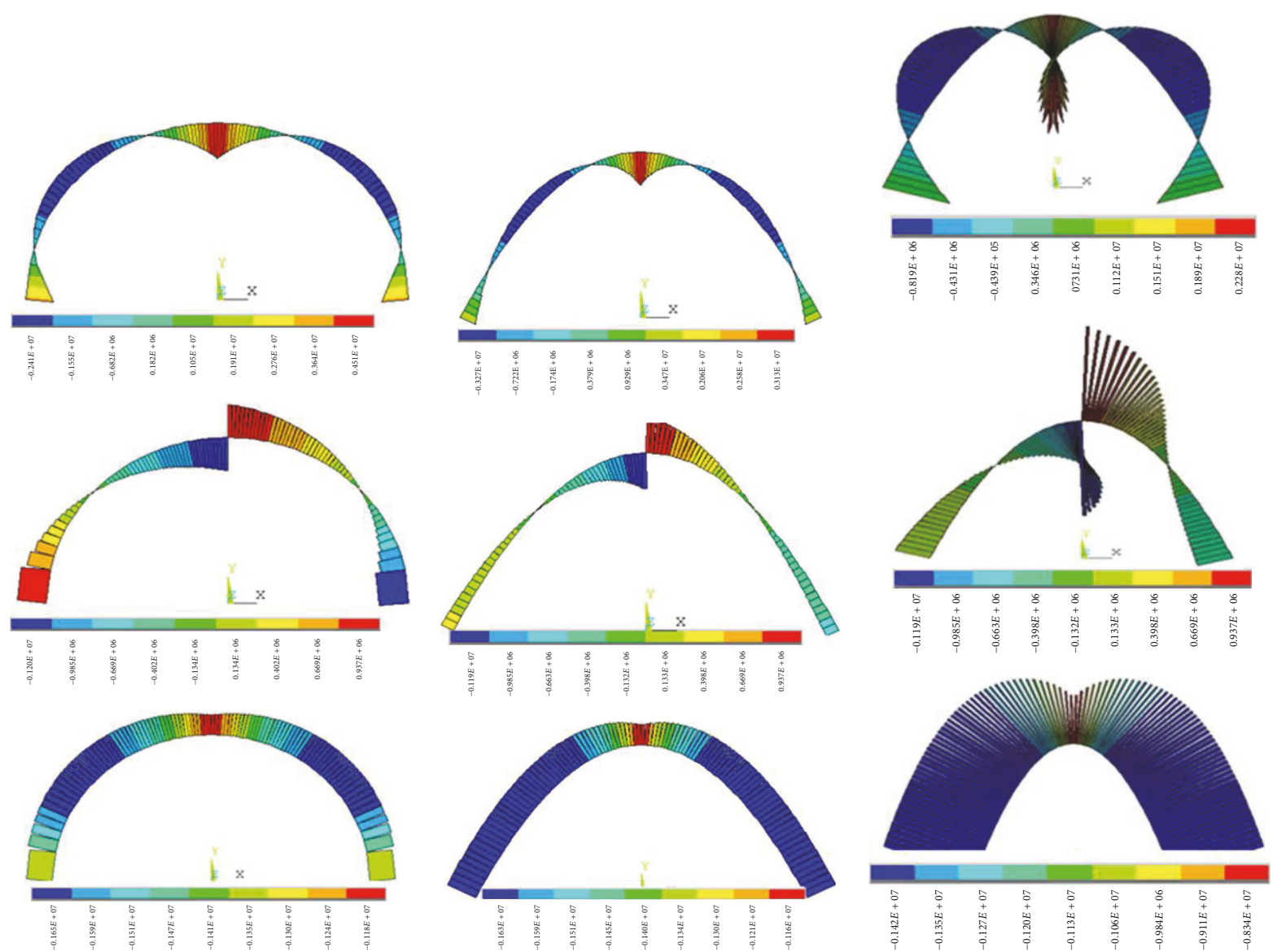

(a)

(b)

(c)

Figure 12: Force contour maps of three different arched structures ( $a, b$, and $c$ are the bending moments, shear forces, and axial forces of the circular curve, Type I parabola, and Type II parabola).

TABLE 3: Forces calculated at the key positions of each arched structure.

\begin{tabular}{|c|c|c|c|c|c|c|c|}
\hline \multirow{3}{*}{ Curve type } & \multicolumn{7}{|c|}{ Quantity } \\
\hline & \multirow{2}{*}{ Vertical displacement at the crown (mm) } & \multicolumn{2}{|c|}{ Bending moment $(\mathrm{kN} \cdot \mathrm{m})$} & \multicolumn{2}{|c|}{ Shear force $(\mathrm{kN})$} & \multicolumn{2}{|c|}{ Axial force $(\mathrm{kN})$} \\
\hline & & Crown & Foot & Crown & Foot & Crown & Foot \\
\hline Circular arc & 27.8 & 5370 & 3824 & 1205 & 982 & 1122 & 1320 \\
\hline \multicolumn{8}{|l|}{ Parabola } \\
\hline Type I & 8.9 & 3681 & 1738 & 1194 & 418 & 1106 & 1573 \\
\hline Type II & 3.6 & 2669 & 1107 & 1194 & 290 & 766 & 1389 \\
\hline
\end{tabular}

the station. The arched wall was constructed using concrete and links the retaining walls of the foundation pit to the piles of the skewed arch. A block that conforms to the curve of the arch was set between the crown and the pile foundations to connect these structures. The block was constructed from the same materials as the arched wall and has the same depth as that of the wall, as shown in Figure 13.

To investigate the effects of reinforcement using arched walls with different heights, we performed numerical analyses on three arched wall heights, using the same construction scenario. The dimensions of the arched walls were as follows: the first arched wall had a height of $5.15 \mathrm{~m}$, and the coordinates of the top and bottom of this wall were $z=-0.8 \mathrm{~m}$ and $z$
$=-5.95 \mathrm{~m}$, respectively. The second arched wall was $9.25 \mathrm{~m}$ high, and the coordinates of the top and bottom of this wall were $z=-0.8 \mathrm{~m}$ and $z=-10.05 \mathrm{~m}$, respectively. The third arched wall was $13.2 \mathrm{~m}$ high, and the coordinates of the top and bottom of this wall were $z=-0.8 \mathrm{~m}$ and $z=-14.0 \mathrm{~m}$, respectively.

We calculated the vertical and horizontal displacements of these arched walls after excavation was completed (i.e., postexcavation) and after loads were applied on the skewed arch pile foundations (i.e., postloading), as shown in Figures 14 and 15. The contour maps illustrating the postexcavation and postloading patterns of horizontal and vertical displacement transfer for each arched wall height are shown in 


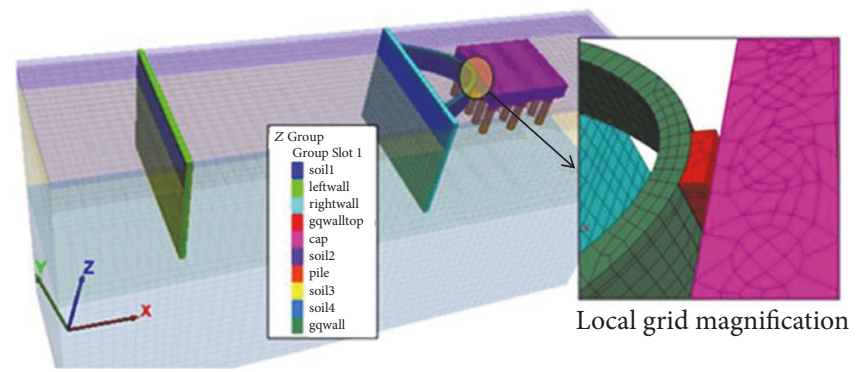

FIGURE 13: Finite element model of the subway foundation pit after reinforcement using an arched wall.

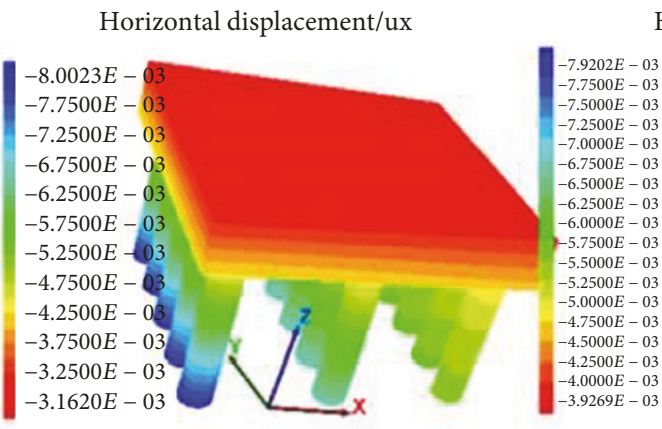

Horizontal displacement/ux

Horizontal displacement/ux

Arch wall height $H=5.15 \mathrm{~m}$

Vertical displacement/ux

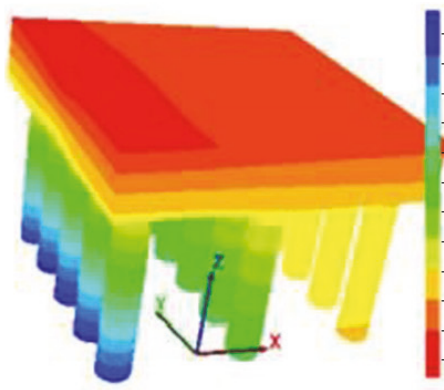

Arch wall height $H=9.25 \mathrm{~m}$

Vertical displacement/ux

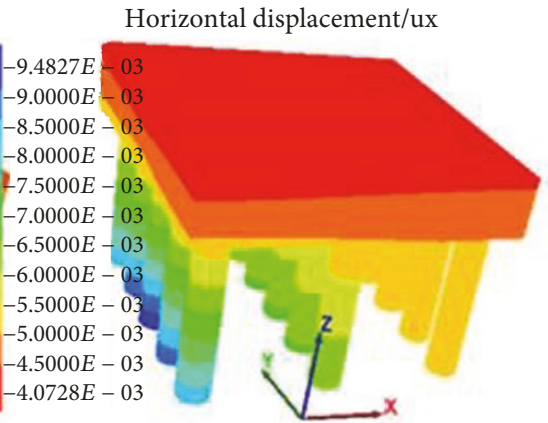

Arch wall height $H=13.2 \mathrm{~m}$

Vertical displacement/ux
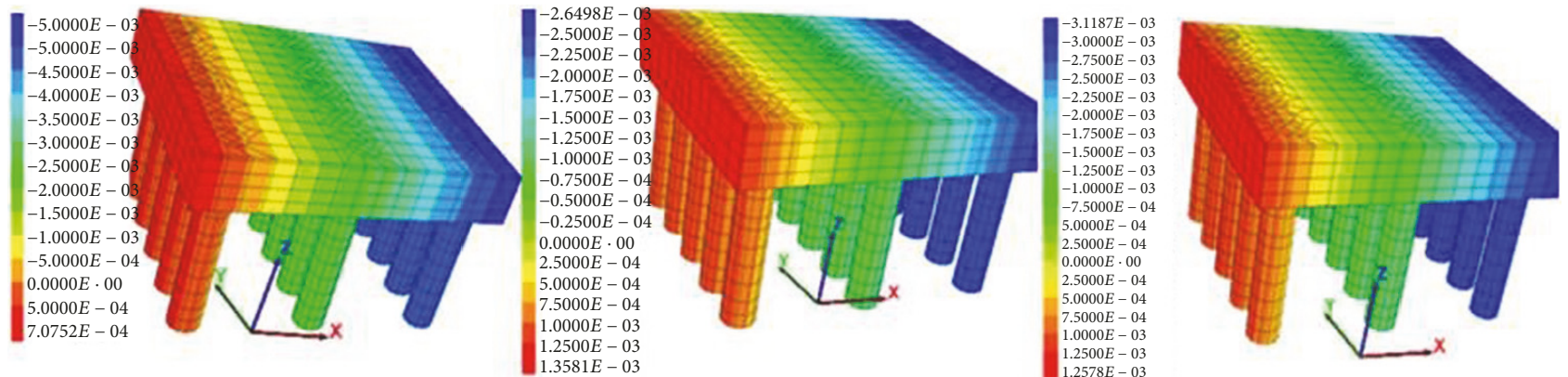

FIGURE 14: Contour maps of the postexcavation pile cap displacements in each scenario.

Figures 16 and 17. It is shown that increases in the height of the arched wall reduce the lateral displacements of the pile cap. When the depth of the arched wall was $13.2 \mathrm{~m}$, the horizontal displacement caused by loading of the skewed arch pile foundations was only $6.44 \mathrm{~mm}$. This is almost the same as the horizontal displacement that was observed with the isolation pile + jet-grouted pile reinforcement, which was $6.03 \mathrm{~mm}$. The difference in displacement between these reinforcement schemes is only $0.41 \mathrm{~mm}$. In terms of vertical displacements, the difference between the two reinforcement schemes is only $0.5 \mathrm{~mm}$. Hence, arched wall reinforcement has effectively controlled the horizontal and vertical displacements of the pile cap. A comparison between the reinforcement effects of the arched walls with different heights quickly reveals that an arched wall height of $13.2 \mathrm{~m}$ produces the best results. In terms of the control of horizontal displacements in the skewed arch piles, the effectiveness of the $13.2 \mathrm{~m}$ arched wall is comparable to that of the isolation pile + jet-grouted pile reinforcement scheme.
4.2.3. The Displacement Responses of the Foundation Pit's Retaining Walls. Under the reinforcement of three different height arch walls, the horizontal displacements of the monitoring point of retaining wall both far away from pile foundation and adjacent to pile foundation are shown in Figure 18. In this figure, it is shown that increases in arched wall height decrease the horizontal displacements of the retaining wall closer to the piles (left figures) and have no effect on the retaining wall far away from the piles. However, the height of the arched wall does not significantly affect the retaining walls (only $2 \mathrm{~mm}$ ), as its effects mainly manifest in the control of the pile foundation displacements.

4.2.4. Mechanical Responses of the Arched Wall. The contour maps of the principal stresses and displacements of a $5.15 \mathrm{~m}$ high arched wall are shown in Figures 19, 20, and 21, respectively. It is shown that the arched wall is highly effective, as the principal stresses of the wall mostly act in the same direction as the tangential lines of the arch curvature. In other 
Horizontal displacement/ux

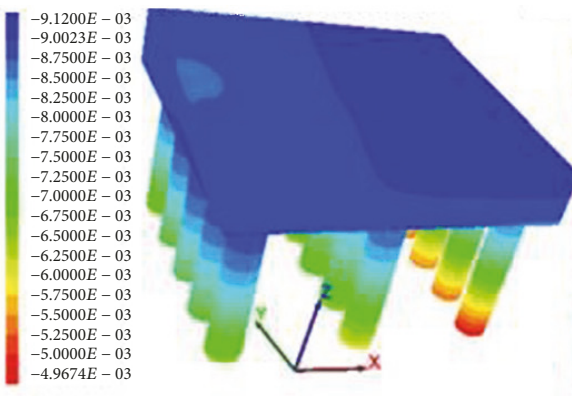

Arch wall height $H=5.15 \mathrm{~m}$

Vertical displacement/ux

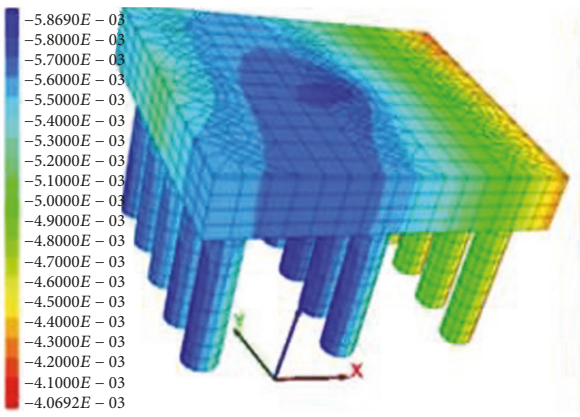

Horizontal displacement/ux

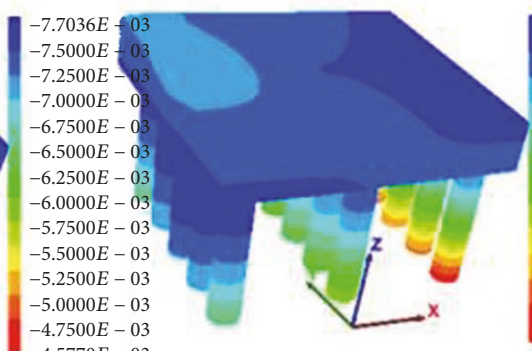

$-4.7500 E-03$

Arch wall height $H=9.25 \mathrm{~m}$

Vertical displacement/ux

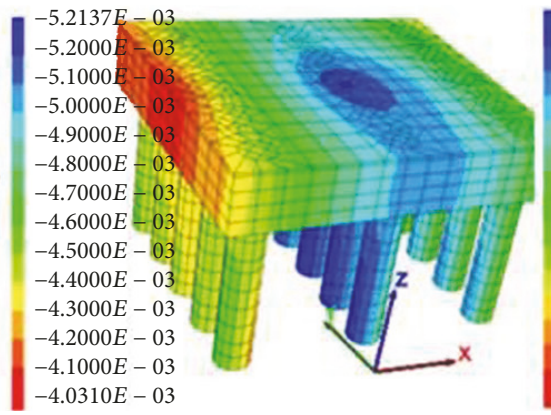

Horizontal displacement/ux

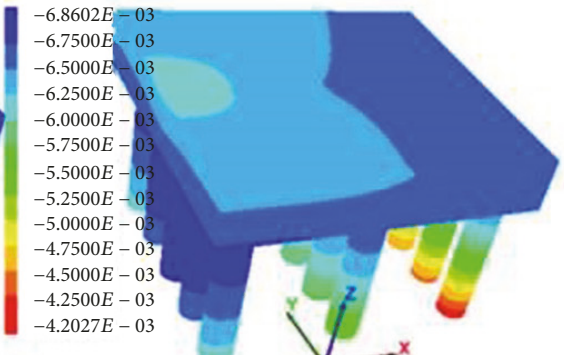

Arch wall height $H=13.2 \mathrm{~m}$

Vertical displacement/ux

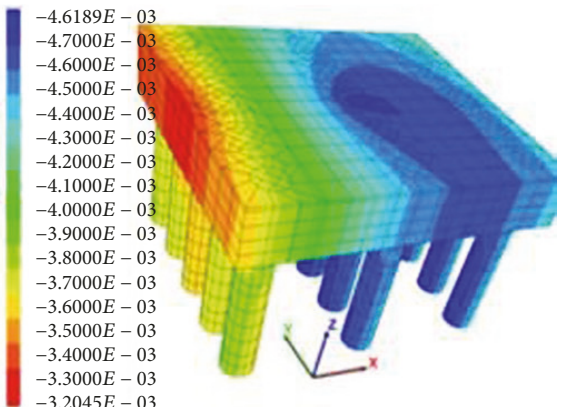

FIGURE 15: Contour maps of the postloading pile cap displacements in each scenario.

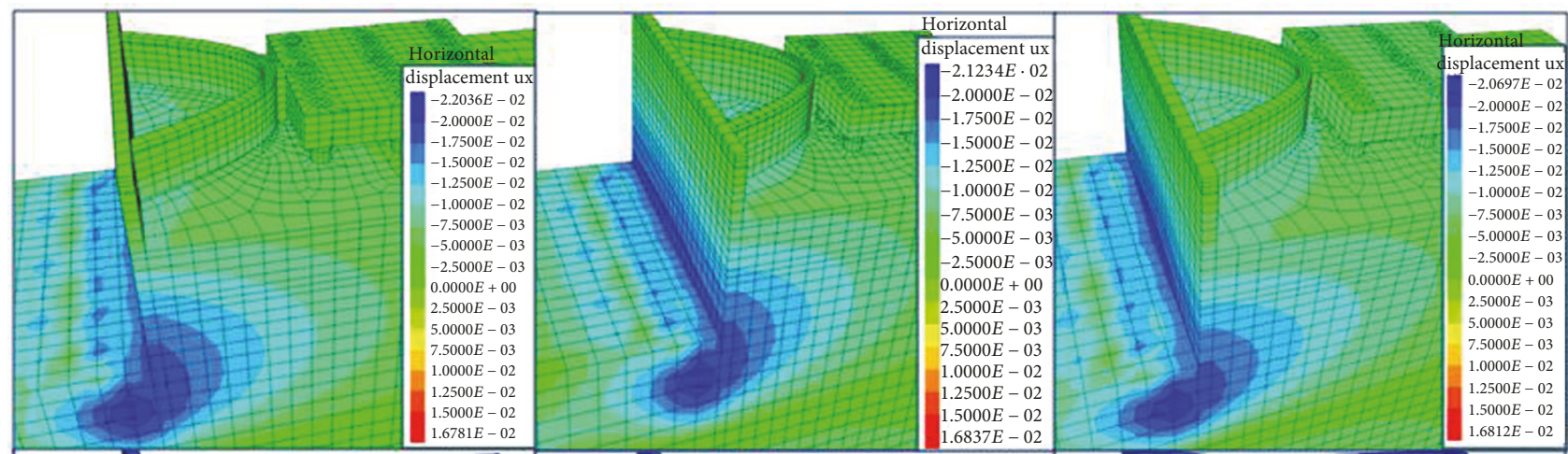

FIGURE 16: Patterns of horizontal and vertical displacement transfer after excavation.

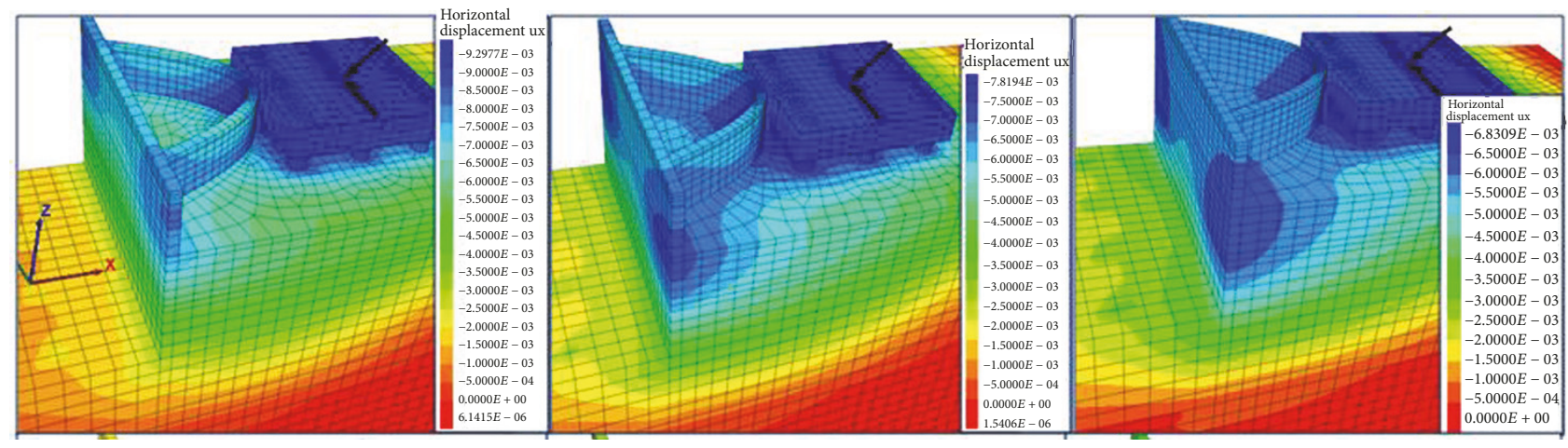

FIGURE 17: Patterns of horizontal and vertical displacement transfer after loading of the pile cap. 

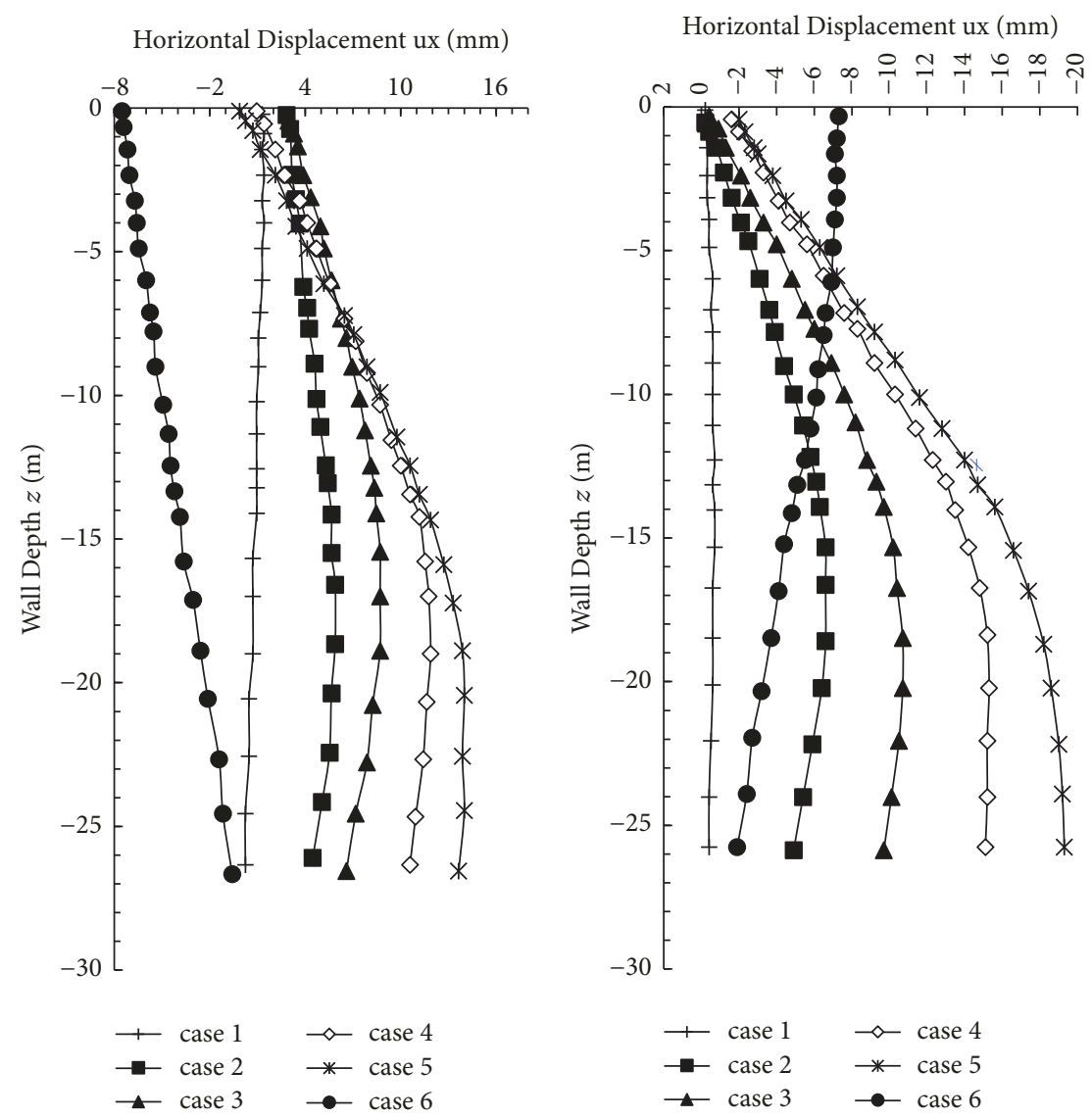

(a) Arched wall height of $5.15 \mathrm{~m}$
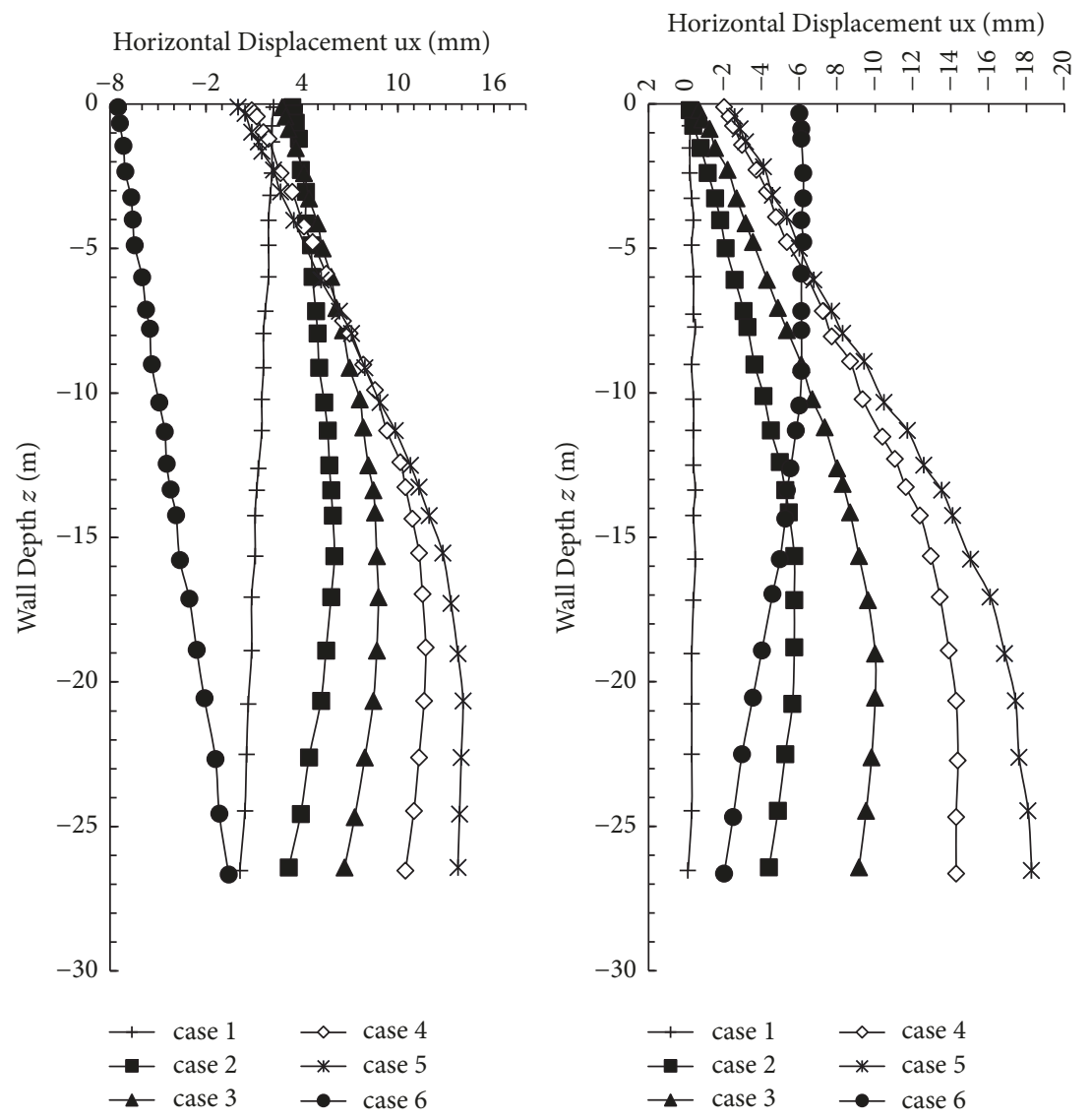

(b) Arched wall height of $9.25 \mathrm{~m}$

Figure 18: Continued. 

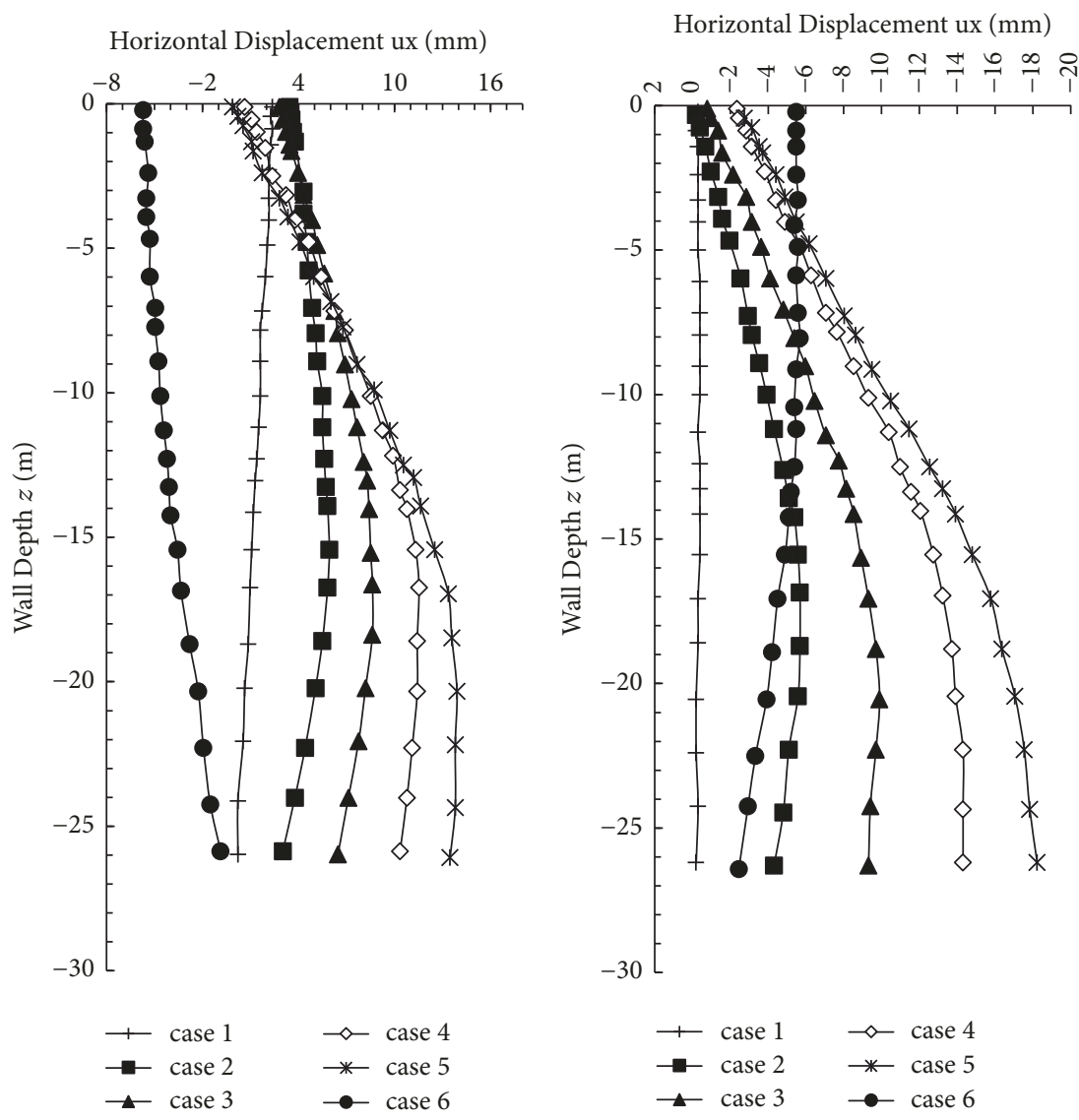

(c) Arched wall height of $13.2 \mathrm{~m}$

FIGURE 18: The horizontal displacement of the monitoring point of retaining wall both far away from (left) and adjacent to (right) pile foundation under the reinforcement of three different height arch walls.

words, the internal compressive stresses of the arched wall are large, which is consistent with the conclusions of our previous structural analysis. It is shown that even if the arched wall is buried in complex soil masses, the pressure exerted by the earth on either side of the arched wall will nullify each other, and the crown of the arch will bear tremendous horizontal reactions. Therefore, the horizontal reactions will be borne by the arched wall, whose stiffness far exceeds that of the soil masses. Based on the forces at the foot of the arch, there is indeed a concentration of stresses around these parts. Nonetheless, these concentrations are not overly significant because the forces at the foot of the arch are transferred to the retaining walls of the foundation pit, which may be approximated as being infinite in length. Hence, excessive deformations and stresses will not occur at the foot of the arch. However, in actual applications, there is a gap between the retaining walls, and the soil masses between the walls cannot effectively transfer the stresses of the arch feet. Therefore, the selection of an appropriate reinforcement scheme for the feet of the arch is necessary. One such example is the installation of interlocked isolation piles. In addition, the three arched walls have similar distributions in displacement, as the displacements are always large on the sides of the wall and small in the middle. As the height of the arched wall increases, the zone of stress concentration on either side of the arched wall gradually expands while the maximum stress gradually decreases.

4.3. Analyzing the Reinforcement Effects of Mounting a Row of Inclined Piles under the Pile Cap (3rd Reinforcement Scheme). To improve the ability of the pile cap foundation to resist horizontal displacements, we changed a pile-row on the pile cap side closer to the foundation pit into inclined piles. Numerical simulations were then performed to compare inclined piles with inclinations of $30^{\circ}, 45^{\circ}$, and $60^{\circ}$. The contour maps of the postexcavation and postloading horizontal and vertical displacements corresponding to these three cases are shown in Figures 22 and 23. Based on the results of the calculations, the horizontal displacement of the pile cap increases significantly after the subway foundation pit was excavated, when the inclinations of the inclined piles were $30^{\circ}, 45^{\circ}$, and $60^{\circ}$. As the overall stiffness of steel supports is lower than that of concrete supports, this may have been caused by the weaker deformation resistance of the steel supports. After the pile cap was loaded, the horizontal displacements caused by the load at the center of the pile cap were $12.60 \mathrm{~mm}\left(30^{\circ}\right)$, $12.58 \mathrm{~mm}\left(45^{\circ}\right)$, and $11.82 \mathrm{~mm}\left(60^{\circ}\right)$. Therefore, inclined piles with an inclination of $60^{\circ}$ produced the best reinforcement of these piles. Without any reinforcement, the horizontal displacement caused by the loading of the pile cap was 


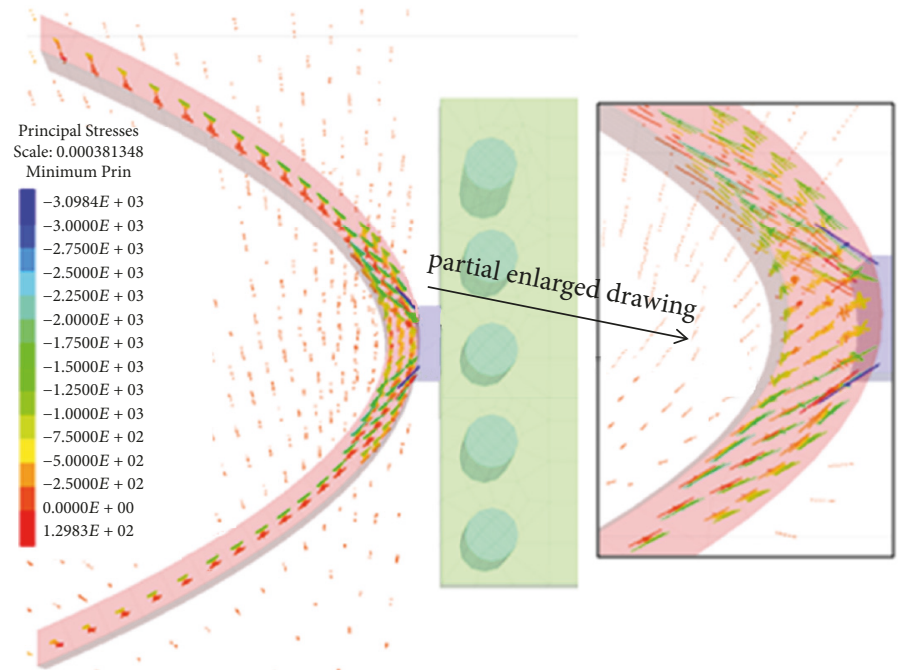

FIGURE 19: Contour map of the postexcavation principal stresses in the arched wall.

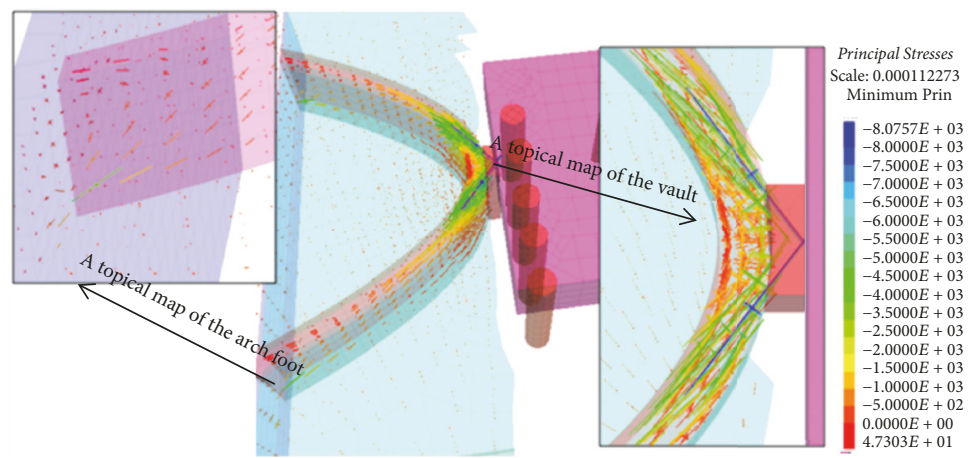

Figure 20: Contour map of the postloading principal stresses in the arched wall.

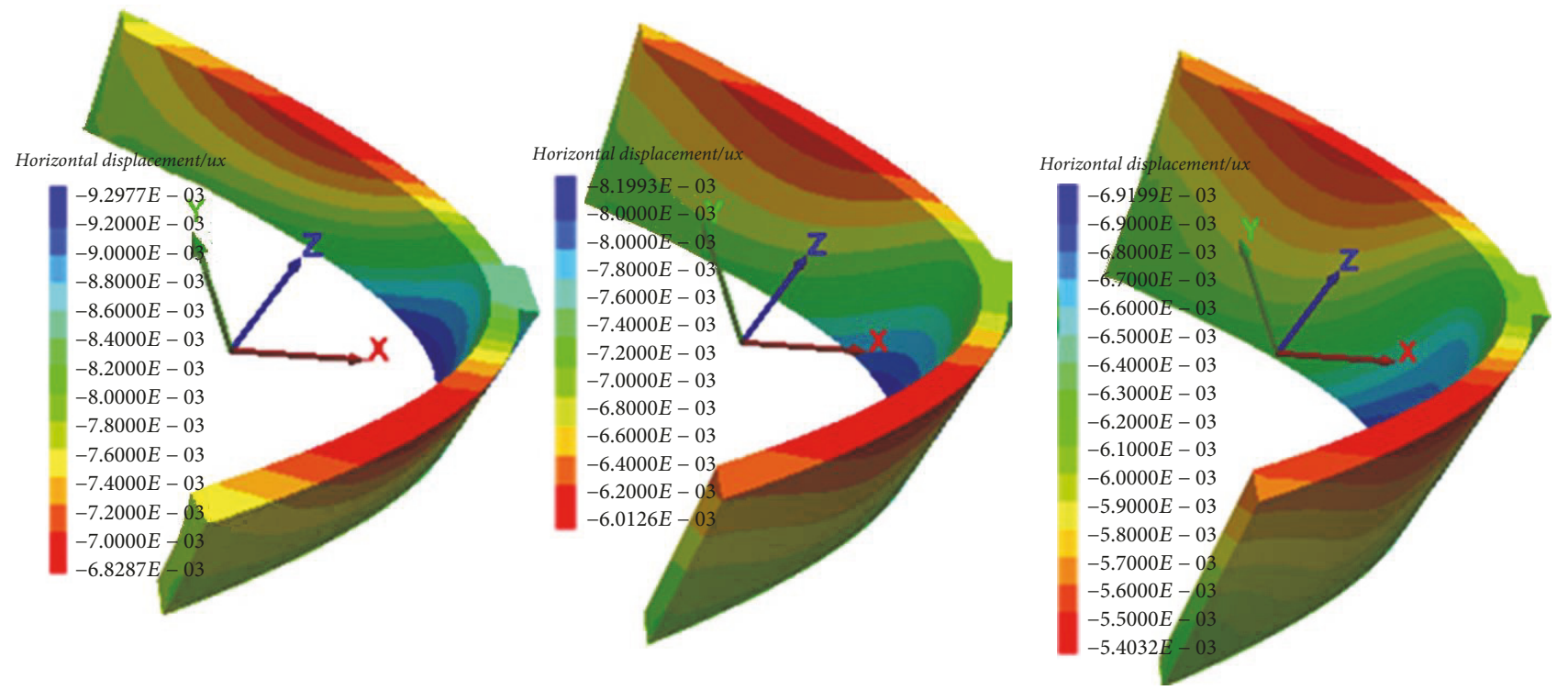

FIGURE 21: The contour map of postloading displacements corresponding to three different arched wall heights does have a certain level of effectiveness in reducing horizontal displacements. 


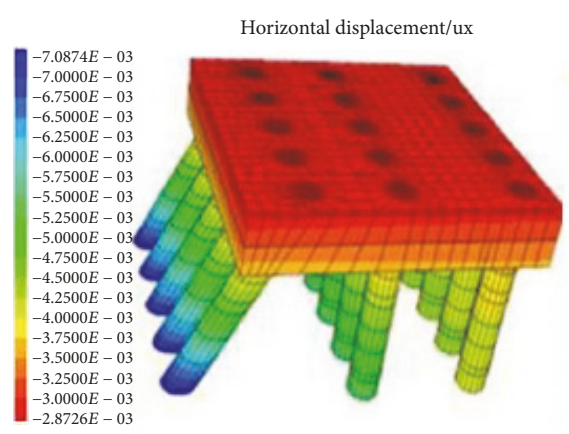

$2.8726 E-03$
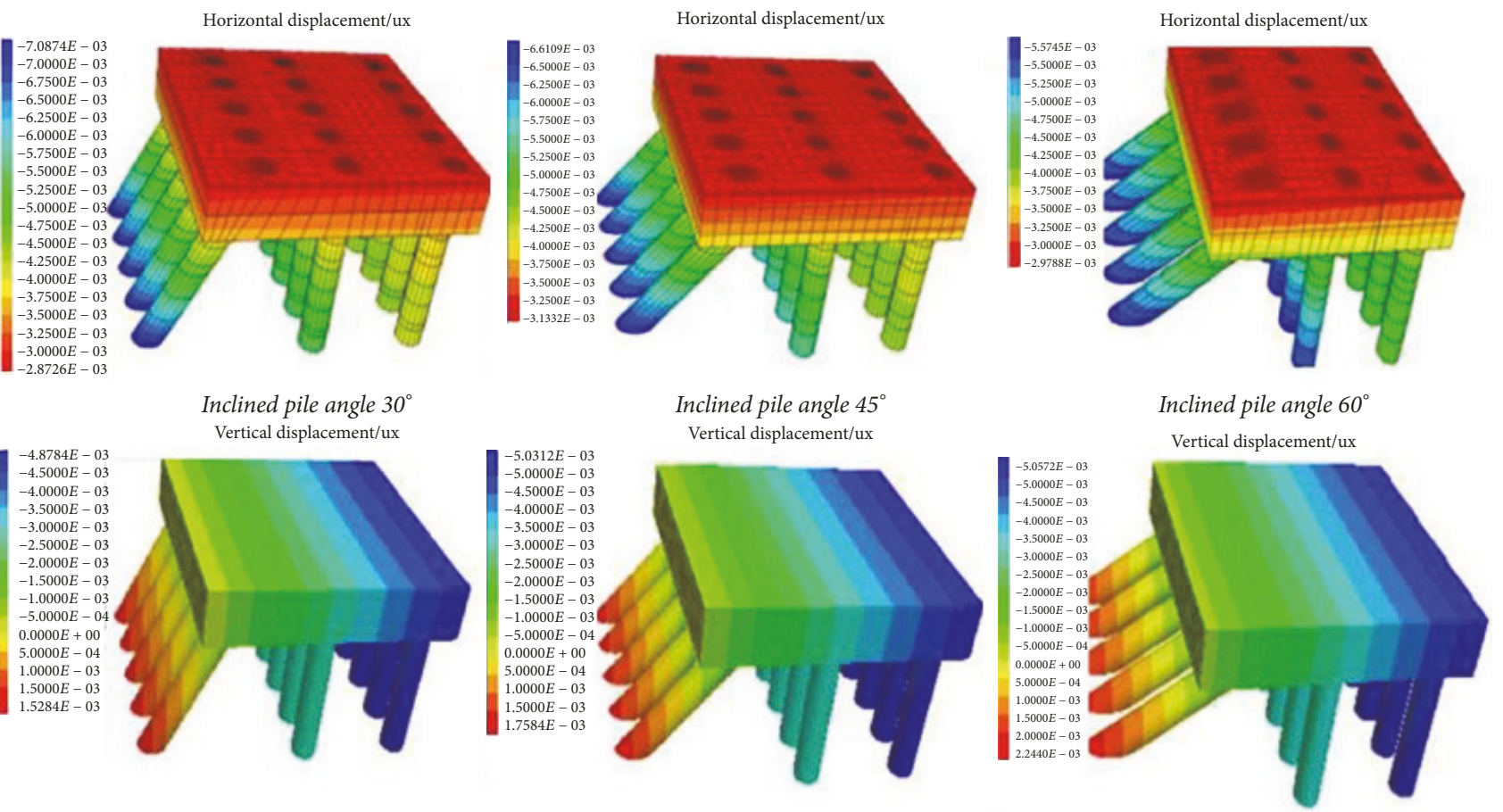

FIGURE 22: Postexcavation contour maps of pile cap displacements in each case.

TABLE 4: The effectiveness of each reinforcement scheme in controlling the horizontal displacement of the pile cap.

\begin{tabular}{|c|c|c|c|c|c|c|c|c|}
\hline \multirow{3}{*}{$\begin{array}{l}\text { Horizontal } \\
\text { displacement }\end{array}$} & \multirow{3}{*}{$\begin{array}{l}\text { Without } \\
\text { reinforcement }\end{array}$} & \multirow{3}{*}{$\begin{array}{l}\text { Reinforcement } \\
\text { via isolation } \\
\text { piles and } \\
\text { jet-grouted piles }\end{array}$} & \multicolumn{3}{|c|}{ Reinforcement scheme } & \multirow{2}{*}{\multicolumn{3}{|c|}{$\begin{array}{c}\text { Setting up inclined piles with } \\
\text { different inclinations under the pile } \\
\text { cap }\end{array}$}} \\
\hline & & & \multicolumn{3}{|c|}{$\begin{array}{l}\text { Reinforcement using arched walls with } \\
\text { different heights }\end{array}$} & & & \\
\hline & & & $\begin{array}{l}\text { Arched wall } \\
\text { height of } \\
5.15 \mathrm{~m}\end{array}$ & $\begin{array}{l}\text { Arched wall } \\
\text { height of } \\
9.25 \mathrm{~m}\end{array}$ & $\begin{array}{l}\text { Arched wall } \\
\text { height of } \\
13.2 \mathrm{~m}\end{array}$ & $\begin{array}{l}\text { Inclination } \\
\text { of } 30^{\circ}\end{array}$ & $\begin{array}{l}\text { Inclination of } \\
45^{\circ}\end{array}$ & $\begin{array}{l}\text { Inclination } \\
\text { of } 60^{\circ}\end{array}$ \\
\hline Postexcavation & 3.82 & 2.92 & 3.32 & 4.23 & 4.41 & 2.93 & 3.21 & 3.05 \\
\hline Postloading & 14.8 & 6.03 & 8.94 & 7.42 & 6.44 & 12.60 & 12.58 & 11.82 \\
\hline
\end{tabular}

$14.80 \mathrm{~mm}$. Hence, the use of inclined piles with an inclination of $60^{\circ}$ reduces the horizontal displacement of the pile cap by $3 \mathrm{~mm}$; therefore, the inclined piles have a significant effect on controlling horizontal displacement. However, when the inclination of the inclined piles was $60^{\circ}$, the projection of the pile onto the vertical axis is only half the length of a vertical pile. Therefore, if the elevation of the bottom end of the inclined piles is maintained at the same level as that of a vertical pile, the suppression of horizontal displacement using inclined piles could be more effective. In summary, this scheme does have a certain level of effectiveness in reducing horizontal displacements.

\subsection{Comparison of the Effectiveness of Each Reinforcement} Scheme in Controlling the Horizontal Displacements of a Pile Cap. The deformations of the skewed arch pile foundations following the application of each reinforcement scheme are shown in Table 4 to facilitate a comparative analysis. The combination of isolation piles and jet-grouted piles is the most effective scheme for limiting horizontal displacements in the skewed arch piles. However, this reinforcement scheme also involves tremendous costs. The arched wall reinforcement scheme is also effective at restricting the horizontal displacements of the piles, and a $13 \mathrm{~m}$ high arched wall is sufficient for achieving excellent results from this aspect. The use of inclined piles under the pile cap also limits horizontal displacements to an extent, but it is not a particularly effective method because the reduction in horizontal displacement was only $\sim 2 \mathrm{~mm}$. Hence, the use of inclined piles alone is insufficient for meeting the needs of engineering applications. In summary, the arched wall reinforcement scheme is the best of the three aforementioned schemes in terms of horizontal displacement control and project costs. Furthermore, the stress states of the arched wall will make full use of an arched structure's advantages.

\section{Conclusions}

To study the interactions between deep foundation pits and the pile foundations of skewed arches, we have performed 
Horizontal displacement/ux

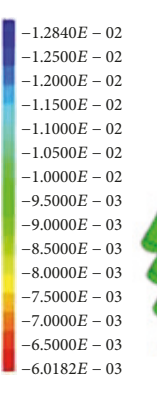

\begin{tabular}{|l} 
\\
$-1.0628 E-02$ \\
$-1.0500 E-02$ \\
$-1.0000 E-02$ \\
$-9.5000 E-03$ \\
$-9.0000 E-03$ \\
$-8.5000 E-03$ \\
$-7.5000 E-03$ \\
$-7.0000 E-03$ \\
$-6.5000 E-03$ \\
$-6.0000 E-03$ \\
$-5.5000 E-03$ \\
$-5.0000 E-03$ \\
$-4.5000 E-03$ \\
$-4.0074 E-03$
\end{tabular}

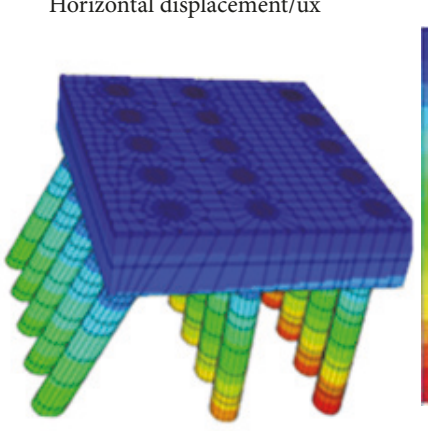

Inclined pile angle $30^{\circ}$

Vertical displacement/ux

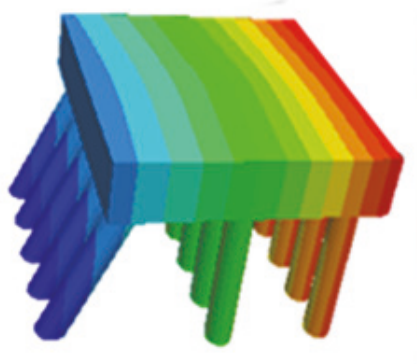

Horizontal displacement/ux

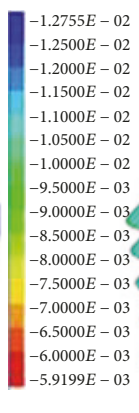

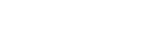

Inclined pile angle $45^{\circ}$

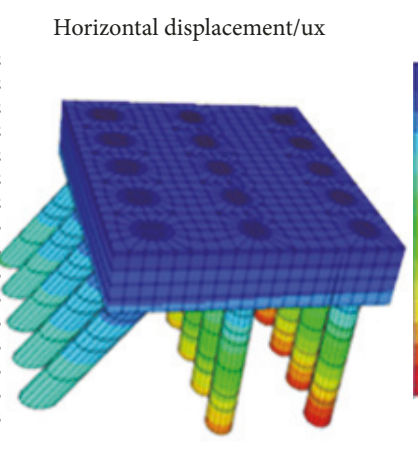

Vertical displacement/ux

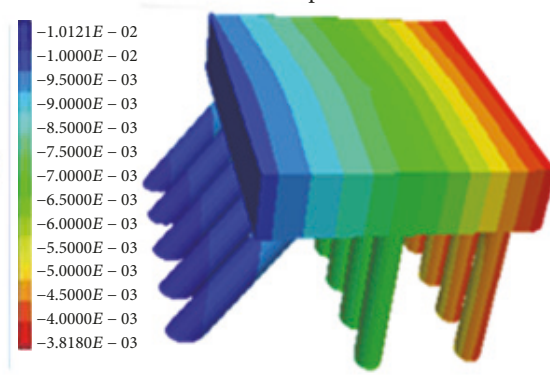

Horizontal displacement/ux

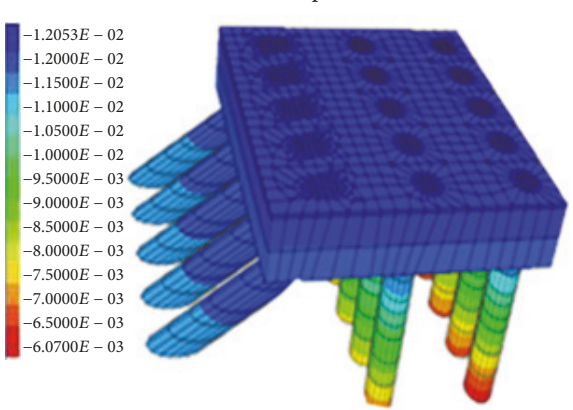

Inclined pile angle $60^{\circ}$

Vertical displacement/ux

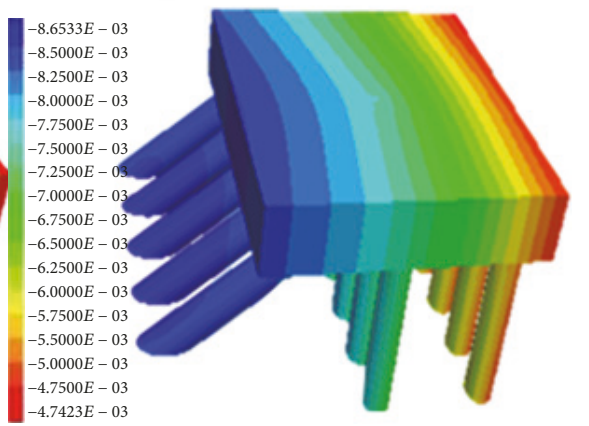

Figure 23: Postloading contour maps of pile cap displacements in each case.

computational analyses on the displacement responses of pile caps and foundation pit retaining walls, which account for a variety of construction scenarios and reinforcement schemes. The computational results indicate that the magnitude of horizontal displacements at the top of the pile foundations is strongly affected by the soil modulus of the upper soils. The mechanisms by which a deep foundation pit interacted with its adjacent pile foundations were revealed. The excavation of deep foundation pits causes the soil masses in its surroundings to move towards the foundation pit, and displacements occur in nearby skewed arch piles, as they lie within the range of influence of the foundation pit. The excavation of the foundation pit effectively undermines the lateral constraints of the skewed arch pile foundations, thus reducing the bearing capacities of the piles to a certain extent. The ground stresses induced by the loading of the skewed arch piles are dispersed within the soil mass, which ultimately leads to the application of additional stresses on the retaining walls of the foundation pit. These additional stresses should be accounted for during the design of the retaining wall structures of the foundation pit. Three techniques for controlling the deformations were considered. The first of these techniques is the use of isolation piles and jet-grouted piles in the upper gravel layer of the soil mass. This technique ensures that deep foundation pits can be constructed safely, mitigates the effects of foundation pit excavation on nearby skewed arch pile foundations, and satisfies the displacement control requirements of skewed arch pile caps. The second technique is a novel arched wall-based reinforcement scheme. The third technique involves the installation of a single row of inclined piles under the pile cap, based on the fact that the piles of a skewed arch are primarily subjected to horizontal loads. The effects of these reinforcement schemes were then compared. The arched wall reinforcement scheme was found to deliver the best outcomes. Furthermore, the stress states of the arched wall made full use of the arched structure's advantages. The findings of this study can be directly applied in the construction and design of subway foundation pits.

\section{Conflicts of Interest}

The authors declare that there are no conflicts of interest regarding the publication of this paper.

\section{Acknowledgments}

This work was supported by the National Natural Science Foundation of China (Grant no. 41572245).

\section{References}

[1] C. F. Leung, D. E. L. Ong, and Y. K. Chow, "Pile behavior due to excavation-induced soil movement in clay. II: Collapsed wall," Journal of Geotechnical and Geoenvironmental Engineering, vol. 132, no. 1, pp. 45-53, 2006.

[2] D. E. L. Ong, C. F. Leung, and Y. K. Chow, "Behavior of pile groups subject to excavation-induced soil movement in very soft clay," Journal of Geotechnical and Geoenvironmental Engineering, vol. 135, no. 10, pp. 1462-1474, 2009.

[3] G. Zheng, Y. Diao, and C. W. W. Ng, "Finite element analysis on mechanism of effect of extra-deep excavation on vertical load transfer and settlement of a single pile," Yantu Gongcheng 
Xuebao/Chinese Journal of Geotechnical Engineering, vol. 31, no. 6, pp. 837-845, 2009.

[4] M. Yang and J. Lu, "A calculation of behavior of underpinning pile subject to excavation of deep foundation pit," Journal of Tongji University, vol. 38, no. 12, pp. 1730-1735, 2010.

[5] L. Wang and G. Zheng, "Performance of piles at pit bottom during excavation of metro station," Electronic Journal of Geotechnical Engineering, vol. 21, no. 3, pp. 907-927, 2016.

[6] A. Yao, X. Yang, and L. Dong, "Numerical analysis of the influence of isolation piles in metro tunnel construction of adjacent buildings," Procedia Earth and Planetary Science, vol. 5, pp. 150-154, 2012.

[7] J.-L. Du and M. Yang, "Elastoplastic solution for excavation-pile interaction," Chinese Journal of Geotechnical Engineering, vol. 30, no. 8, pp. 1121-1125, 2008.

[8] F.-Q. Chen, J.-W. Wang, and Y.-C. Liu, "Numerical analysis of pile response due to braced excavation-induced soil lateral movement," Rock and Soil Mechanics, vol. 29, no. 7, pp. 19711976, 2008.

[9] J. Du L and M. Yang, "Deflection control analysis of pile adjacent to deep excavation," in Structural Engineers, vol. 24, pp. 93-99, 5 edition, 2008.

[10] G. Zheng, Z.-X. Yan, H.-Y. Lei, and Y. Lei, "Field observation and finite element numerical simulation analysis of effect on adjacent piles due to excavation," Chinese Journal of Geotechnical Engineering, vol. 29, no. 5, pp. 638-643, 2007.

[11] M. Zheng X, Y. Xia M, and Q. Yuan, "Deformation analysis of pile of bridge piers of high-speed railway affected by adjacent deep foundation excavation," Construction Technology, vol. 46, no. 5, pp. 12-16, 2017.

[12] X.-N. Gong, J.-C. Wang, and C.-J. Wu, "Effect of unloading on the shaft resistance of existing piles due to deep excavation," Journal of Hunan University Natural Science, vol. 41, no. 6, pp. 70-76, 2014.

[13] D. E. L. Ong, C. E. Leung, and Y. K. Chow, "Pile behavior due to excavation-induced soil movement in clay. I: Stable wall," Journal of Geotechnical and Geoenvironmental Engineering, vol. 132, no. 1, pp. 36-44, 2006.

[14] R. Zhang, J. Zheng, H. Pu, and L. Zhang, "Analysis of excavation-induced responses of loaded pile foundations considering unloading effect," Tunnelling and Underground Space Technology, vol. 26, no. 2, pp. 320-335, 2011.

[15] C. J. Lee, "Numerical analysis of the interface shear transfer mechanism of a single pile to tunnelling in weathered residual soil," Computers \& Geosciences, vol. 42, pp. 193-203, 2012.

[16] E. Bilotta and G. Russo, "Use of a line of piles to prevent damages induced by tunnel excavation," Journal of Geotechnical and Geoenvironmental Engineering, vol. 137, no. 3, pp. 254-262, 2010.

[17] T. G. Sitharam, V. B. Maji, and A. K. Verma, "Practical equivalent continuum model for simulation of jointed rock mass using FLAC3D," International Journal of Geomechanics, vol. 7, no. 5, pp. 389-395, 2007.

[18] R. Kumar, D. Choudhury, and K. Bhargava, "Response of Shallow Foundation in rocks subjected to underground blast loading using FLAC3D," Disaster Advances, vol. 7, no. 2, pp. 6471, 2014.

[19] J. Lee, H. Cho, K. You, and S. Jeong, "A Study on the Ultimate Point Resistance of Rock Socketed Drilled Shafts Using FLAC3D and UDEC," Journal of the Korean Geotechnical Society, vol. 28, no. 1, pp. 29-39, 2012.
[20] F. P. Schumacher and E. Kim, "Evaluation of directional drilling implication of double layered pipe umbrella system for the coal mine roof support with composite material and beam element methods using FLAC 3D," Journal of Mining Science, vol. 50, no. 2, pp. 335-348, 2014.

[21] K. Cui and T. Qin X, "Virtual reality research of the dynamic characteristics of soft soil under metro vibration loads based on BP neural networks," Neural Computing \& Applications, pp. 1233-1242, 2017. 


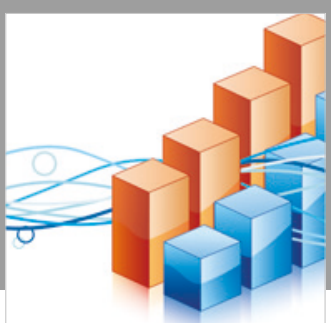

Advances in

Operations Research

\section{-n-m}
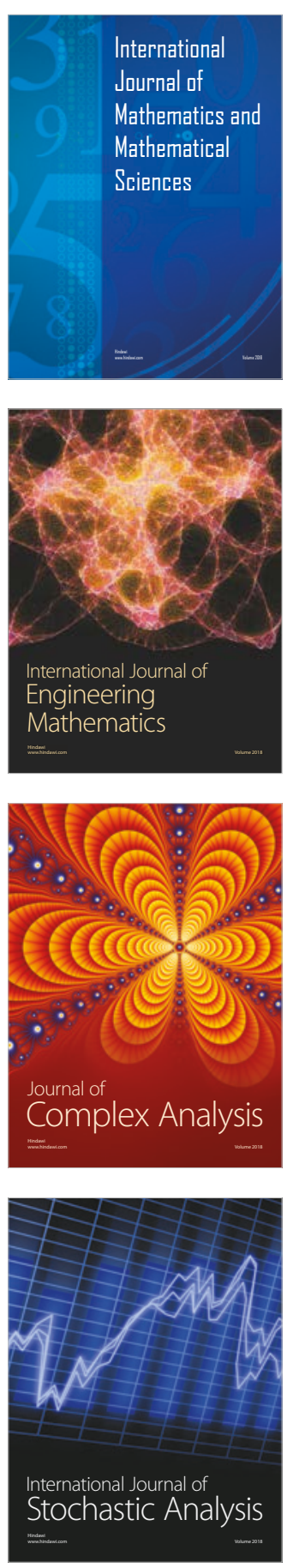
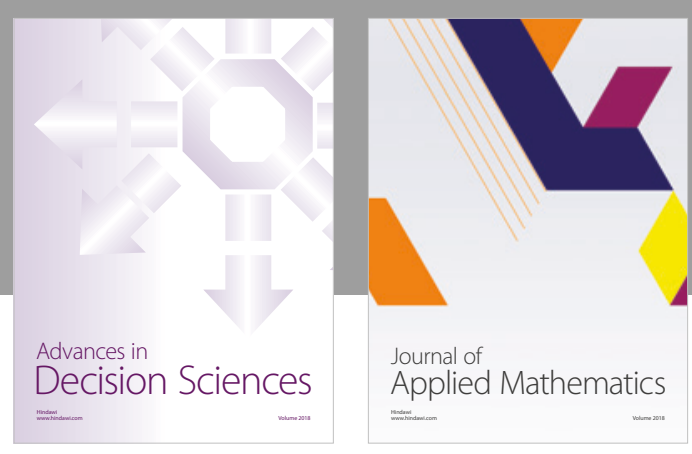

Journal of

Applied Mathematics
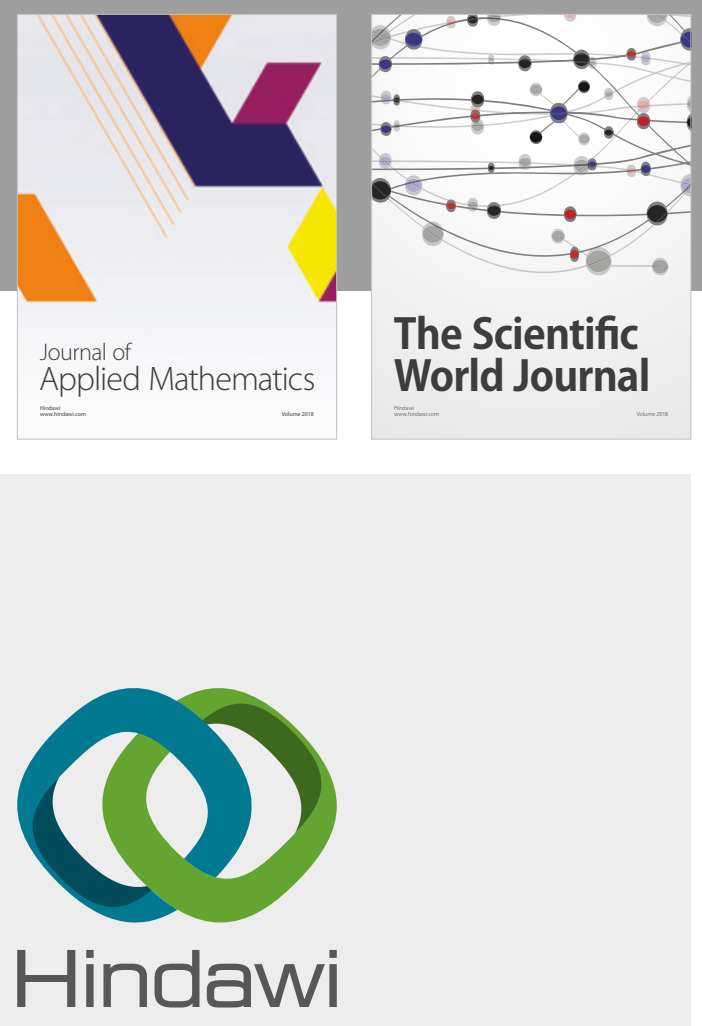

Submit your manuscripts at

www.hindawi.com

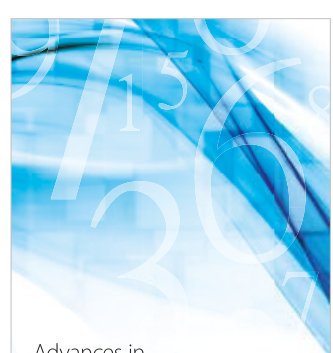

Advances in
Numerical Analysis
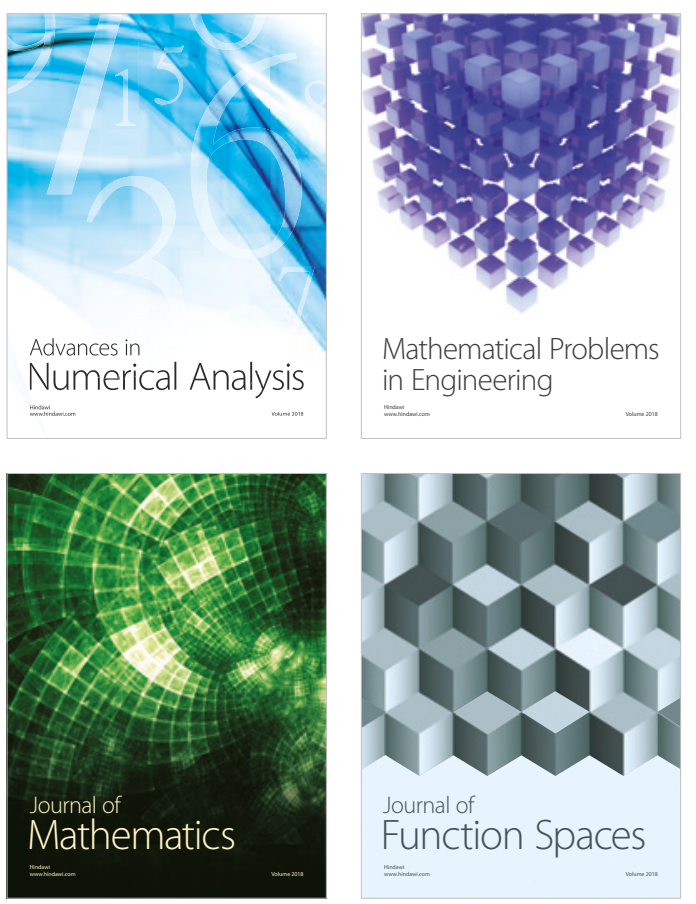

Mathematical Problems in Engineering

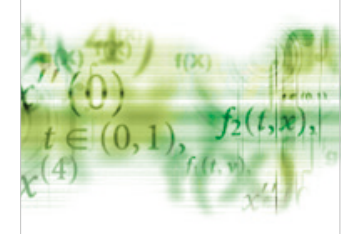

International Journal of

Differential Equations

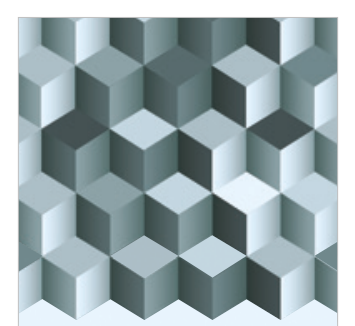

Journal of

Function Spaces
The Scientific

World Journal

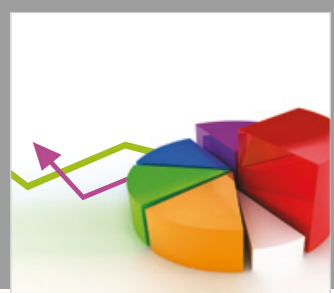

Journal of

Probability and Statistics
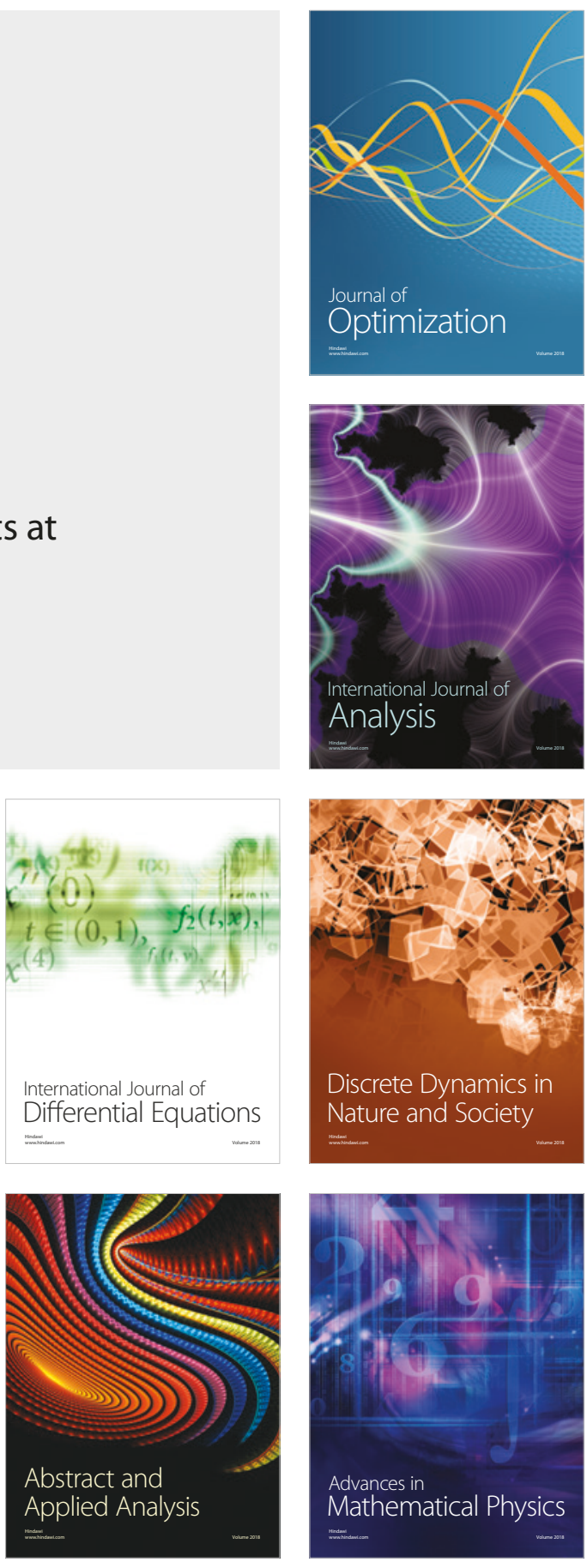